\title{
Una pugna constante entre las provincias de Magangué y Mompox. Decadencias, auges, organización territorial y disputas, 1853-1875
}

\author{
A constant pugna between the provinces of Magangué and Mompox. \\ Decadencies, auges, territorial organization and disputes, 1853-1875 \\ Uma luta constante entre as províncias de Magangué e Mompox. \\ Declínio, boom, organização territorial e disputas, 1853-1875
}

\author{
Eloy Miranda Gil ${ }^{1}$ \\ Institución Educativa de Playitas, Bolívar, Colombia.
}

Para citaciones: Miranda, E. (2020). Una pugna constante entre las provincias de Magangué y Mompox. Decadencias, auges, organización territorial y disputas, $1853-$ 1875. El taller de la Historia, 12(2), 400-432.

Recibido: Julio de 2020

Aprobado: Septiembre de 2020

Autor de correspondencia:

Eloy Miranda Gil

elmigi69@hotmail.com

Editor: Sergio Paolo Solano. Universidad de Cartagena-Colombia.

Tipología IBN Publindex:

Artículo de Investigación
Copyright: (๑) 2020. Miranda, E. Este es un artículo de acceso abierto, distribuido bajo los términos de la licencia https://creativecommons.org/licenses/bync-sa/4.0/ la cual permite el uso sin restricciones, distribución y reproducción en cualquier medio, siempre y cuando que el original, el autor y la fuente sean acreditados.

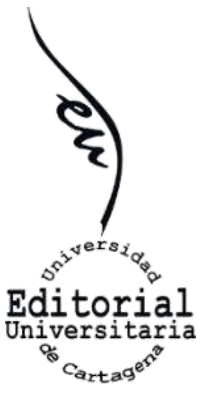

\section{RESUMEN}

El presente artículo pretende demostrar, por un lado, que el desarrollo de Magangué y el estancamiento de Mompox hizo que se generaran disputas en la subregión momposina y, por otro lado, la organización territorial al interior de las provincias llevó al problema de la disolución de algunos distritos que carecían de los elementos básicos que impuso la provincia y el Estado Soberano para seguir ostentando dicho título y a la emanación de algunas aldeas que por sus características debían obtenerlo. Es decir, se mira como sus distritos, aldeas y cantones pujaban por mantener sus categorías territoriales y/o luchaban por una categoría mayor. Además, esta organización desencadenó conflictos entre las dos provincias, puesto que, no estaban definidos con claridad los límites jurisdiccionales de ambas.

Palabras clave: Organización territorial; disputas provinciales; decadencias; auges; Magangué; Mompox; relaciones de poder; actores sociales; distritos; aldeas.

\begin{abstract}
This article aims to demonstrate, on the one hand, that the development of Magangué and the stagnation of Mompox caused disputes to be generated in the Momposina subregion and, on the other hand, the territorial organization within the provinces led to the problem of the dissolution of some districts that lacked the basic elements imposed by the province and the Sovereign State to continue holding that title and the emanation of some villages that due to their characteristics had to obtain it. In other words, it is seen how their districts, villages and cantons tried to maintain their territorial categories and/or fought for a higher category. In addition, this organization triggered conflicts between the two provinces, since the jurisdictional limits of both were not clearly defined.
\end{abstract}

Keywords: Territorial organization; provincial disputes; declines; booms; Magangué; Mompox; power relations; social actors; districts; villages.

${ }^{1}$ Historiador. Docente en la Institución Educativa de Playitas, San Martin de Loba (Bolívar) 


\section{RESUMEM}

Este artigo procura demonstrar, por um lado, que o desenvolvimento de Magangué e a estagnação de Mompox geraram disputas na sub-região de Momposina e, por outro lado, a organização territorial dentro das províncias levou ao problema de dissolução de alguns distritos que careciam dos elementos básicos impostos pela província e pelo Estado Soberano para continuar segurando aquele título e a emanação de algumas aldeias que pelas suas características deviam obtê-lo. Ou seja, vê-se como seus distritos, vilas e cantões pressionaram para manter suas categorias territoriais e / ou lutaram por uma categoria superior. Além disso, esta organização gerou conflitos entre as duas províncias, uma vez que os limites jurisdicionais de ambas não estavam claramente definidos.

Palavras-chave: Organização territorial; disputas provinciais; declínios; booms; Magangué; Mompox; relações de poder; atores sociais; distritos; aldeias.

\section{Presentación}

Desde que Marc Bloch ${ }^{2}$ y Lucien Febvre ${ }^{3}$ se idearon la historia comparativa en la escuela de los annales, para tratar de establecer las singularidades que tiene la Historia de un campo de estudio analizado (un proceso histórico, la evolución económica y social de una ciudad, un país, una región, etc.), entonces la historiografía ha tomado un vuelco hacia el análisis de ello, lo que permite construir generalizaciones acerca del campo histórico que ha sido objeto de estudio a través del método comparativo ${ }^{4}$. Algunos de los estudios que siguen esta línea investigativa, y que nos han influenciado a emprender nuestra investigación desde esta perspectiva, han sido los realizados por Peter Burke, quien se encargó del análisis comparativo de dos ciudades de la Europa occidental: Venecia y Ámsterdam ${ }^{5}$. Así mismo el realizado por Theodore Nichols a las tres ciudades del Caribe colombiano ${ }^{6}$. Además los realizados por Sergio Paolo Solano y Alfonso Múnera ${ }^{7}$.

De otro lado, hablar de estudios sistemáticos referentes al Estado Soberano de Bolívar ${ }^{8}$ años atrás hubiese sido complejo, ya que en ese entonces solo hubiéramos encontrado algunas referencias a él, en algunos artículos y libros, debido a su ubicación temporal en la historia nacional. Verbigracia, el tomo IV de la "historia general de Cartagena" de Eduardo Lemaitre, quien lo

\footnotetext{
${ }^{2}$ Marc Bloch, Introducción a la Historia, México-Madrid-Buenos Aires, Fondo de Cultura Económica, 1952; La sociedad feudal: la formación de los vínculos de dependencia, México, UTEHA, 1958; La sociedad feudal: las clases y el gobierno de los hombres, México, UTEHA, 1958; Historia rural francesa, Crítica-Grijalbo, Barcelona, 1978; "El método comparativo en historia", en Perspectivas de la historiografía contemporánea, SEP, México, 1976.

${ }^{3}$ Lucien Febvre, La tierra y la evolución humana, Cervantes, Barcelona, 1925; Lucien Febvre, y Albert Demangeon, Le Rhin. Problèmes d'histoire et d'Economie, Librairie Armand Colin, París, 1935.

${ }^{4}$ M. Bloch, "El método comparativo en historia"; Carlos Aguirre Rojas, "La corriente de los Annales y su contribución al desarrollo de la historia económica en Francia", en Cuadernos de Trabajo, 3, 1998.

${ }^{5}$ Peter Burke, Venecia y Ámsterdam. Estudio sobre las elites del siglo XVII, Barcelona, Gedisa Ed., 1996.

${ }^{6}$ Theodore E. Nichols, Tres puertos de Colombia estudio sobre el desarrollo de Cartagena, Santa Marta y Barranquilla, Bogotá, 1973.

${ }^{7}$ Sergio Paolo Solano, Puertos, sociedad y conflicto en el Caribe colombiano, 1850-1930, Bogotá, Ministerio de CulturaObservatorio del Caribe colombiano-Universidad de Cartagena, 2003; Alfonso Múnera, El fracaso de la Nación. Región clase y raza en el Caribe colombiano, 1717-1821, Bogotá, Editorial Planeta, 2008.

${ }^{8}$ Las provincias de Magangué y Mompóx hacían parte de este Estado, por lo que este artículo contribuirá en el análisis de dichas provincias y a ampliar la historiografía de dicho estado.
} 
referenció sólo al momento en que se detuvo a hacer mención sobre Juan José Nieto. Lo mismo hallamos en los trabajos de: Jorge Restrepo y Manuel Rodríguez, Eduardo Posada Carbó, Orlando Fals Borda, y, a esta lista les sumamos los realizados por Grey Verbel y por Luz Dary Calvo de Hoyos ${ }^{9}$.

Sin embargo, hoy gracias a los trabajos realizados por algunos historiadores de las universidades del Caribe colombiano podemos encontrar estudios más concretos referentes al tema. Alberto Wong Hiu en $1999^{10}$ fue pionero en estos estudios; y fue seguido por Sergio Paolo Solano y Roicer Flórez. Estos académicos, han analizado los distintos grupos sociales y los conflictos políticos, sociales y económicos acaecidos durante el periodo de funcionamiento de la federación colombiana, al interior del Estado Soberano de Bolívar ${ }^{11}$.

Pero quien más se ha dedicado a profundizar en el estudio de este Estado ha sido Roicer Flórez empezando por analizar las formas cómo funcionaba el poder en el Estado hasta llegar a examinarlo desde el desarrollo social, económico y político ${ }^{12}$. En una de sus investigaciones muestra cuales fueron las principales fortalezas que supuso para el Estado la adopción de la descentralización política, administrativa y económica entre 1857-1886 ${ }^{13}$. Gracias a esos estudios hoy podemos tener un mayor acercamiento a la economía, la sociedad y a el funcionamiento de la política en el Estado Soberano de Bolívar.

Ahora bien, las provincias de Magangué y Mompox han sido escasamente estudiadas por la historiografía nacional. De Magangué, se han preocupado historiográficamente: Eduardo Posada Carbó, en su texto El Caribe Colombiano. Una historia regional (1870-1930), ${ }^{14}$ el cual fue uno de los primeros libros de la academia que presentó a la ciudad de Magangué como

\footnotetext{
${ }^{9}$ Eduardo Lemaitre, Historia General de Cartagena, Bogotá, Banco de la República, 1983, Tomo IV; Jorge Restrepo y Manuel Rodríguez, "La actividad comercial y el grupo de comerciantes de Cartagena a finales del siglo XIX", en Estudios Sociales, 1, 1986; Eduardo Posada Carbó, El Caribe colombiano. Una historia regional, 1870-1950, Bogotá, Banco de la República/El Áncora Editores, 1998; Orlando Fals Borda, El Presidente Nieto, Bogotá, Universidad Nacional/Banco de la República/ El Áncora Editores, 2002; Grey Verbel, "Elites y redes de poder en torno al proyecto regenerador. Cartagena, 1874-1892”, en El Taller de la Historia, 1, 2009; Luz Dary Calvo, Juan José Nieto. Regionalismo y Poder político en el Estado de Bolivar, 1858-1866. Tesis para optar título de historiadora Universidad de Cartagena, 2002.

${ }^{10}$ Alberto Wong Hiu, "Las finanzas públicas en el Estado Soberano de Bolívar, 1857-1886", en Historia y Pensamiento, 3 , 1999, pp. 28-36.

11 Sergio Paolo Solano y Roicer Flórez, "Resguardos indígenas ganadería y conflictos sociales en el Bolívar Grande, 1850 1875", en Historia Crítica, 34, 2007, pp. 92-117; "Indígenas, mestizaje, tierra y poder en el Caribe colombiano, siglo XIX", en Indiana, 26, 2009; "La expropiación de las tierras del resguardo de Tubará y las normas jurídicas de la época", en Justicia, 12, 2007, pp. 81-89; véase también el realizado por William Malkún, Educación y política en el Estado Soberano de Bolívar 1857-1886, Cartagena, Tesis de maestría en historia, Universidad de Cartagena-Universidad Pedagógica y Tecnológica de Colombia, 2008.

${ }^{12}$ Roicer Flórez Bolívar, El uso privado de la autoridad pública en el Estado Soberano de Bolívar, 1863-1878, Cartagena, Tesis para optar el título de Magister en Historia Universidad Pedagógica de Tunja-Universidad de Cartagena, 2007; "Resguardos indígenas, ciudadanía y ganadería en el Estado Soberano de Bolívar, 1863-1875", en Trenzado, 1, 2008; "Indígenas y ciudadanía en el Estado Soberano de Bolívar, 1863-1875", en Historia y Sociedad, 16, 2009, pp. 49-72; "El sistema de arrendamiento y la monopolización de los ingresos fiscales en el Estado Soberano de Bolívar, 1860-1878”, en El Taller de la Historia, 1, 2009, pp. 13-40; "Caña de azúcar y aguardiente en el Estado Soberano de Bolívar, 1857-1886", en Cuadernos de Desarrollo Rural, 6, Bogotá, 2009, pp. 35-57; Región y autonomía en el Caribe colombiano. El caso del Estado Soberano de Bolívar, 1857-1886. Proyecto ganador de la XII convocatoria de las becas de investigación cultural Héctor Rojas Herazo del Observatorio del Caribe Colombiano.

${ }^{13}$ R. Flórez, Región y autonomía en el Caribe colombiano.

${ }^{14}$ Eduardo Posada Carbó, El Caribe Colombiano. Una historia regional (1870-1930), Bogotá, El Áncora Editores/Banco de la República, 1998.
} 
el núcleo económico y social que fue para el período mencionado. Por otro lado, Cristian Roa Valdelamar, en su estudio sobre las ferias comerciales y ganaderas que se daban en esa población, muestra el desarrollo comercial que había alcanzado en la segunda mitad del siglo XIX. ${ }^{15}$ Y José Fernando Meneses en su tesis de pregrado examina el proceso histórico de la inmigración italiana en Colombia de finales del siglo XIX y comienzos del $\mathrm{XX}$, centrándose en el estudio concreto y pormenorizado de su accionar socioeconómico en una ciudad intermedia como Magangué, entre los años de 1890 y 1930, uno de los muchos centros urbanos en los que se establecieron en el país y desde donde trataron de hacer la América en Colombia. ${ }^{16}$

Mompox tiene una diversa historiografía, o más bien se hace referencia a la ciudad por sus gestas en la batalla de independencia y por la importancia que tuvo en la época colonial, ya que servía de tránsito entre Cartagena y el interior del virreinato. ${ }^{17}$ Orlando Fals Borda en su interés por la historia de la región caribe, es quien más resalta la importancia de la ciudad en la vida política, económica y social del país y le dedica uno de sus tomos de su Historia Doble de la Costa. ${ }^{18}$

Pero, concerniente a las relaciones que se generaban entre estas dos provincias encontramos el artículo realizado por Sergio Paolo Solano, Roicer Flórez y William Malkún, en donde hacen mención a algunos de los conflictos de las provincias de Magangué y Mompox ${ }^{19}$. Pero no se enfocan en el análisis de estas dos provincias, ya que su interés no estaba dirigido a ello, sino a todas las del Estado Soberano en general.

Magangué, en ese periodo, entra en un ascenso político, económico y social en esa subregión (la depresión momposina), por lo tanto, Mompox tuvo que afrontar y compartir el poder que en antaño ahí ejercía. ${ }^{20}$ Esto, debido a que, como lo señala el gobernador del Estado Soberano de Bolívar en 1858,

\footnotetext{
${ }^{15}$ Cristian Roa Valdelamar, Ferias comerciales de Magangué (1858-1902), Cartagena, tesis para optar título de historiador, Universidad de Cartagena, 2002.

${ }^{16}$ José Meneses Urzola, Presencia e influencia italiana en Colombia: El caso de Magangué, 1890-1930. Redes sociales y circuitos comerciales, Medellín, trabajo presentado para optar al título de Historiador, Universidad de Antioquia, 2009. Otros textos con referencia a la ciudad de Magangué son: Alfonso del Valle Porto, Compendio monográfico de la villa de Magangué, Medellín, 1992; Luis Striffler, El rio San Jorge Cartagena, 1958; Stella Salazar y Eduardo Aldana, "Magangué en la encrucijada", en Fabio Zambrano Pantoja, (comp.), Poblamiento y ciudades del Caribe colombiano, Bogotá, Observatorio del Caribe Colombiano/Fonade/Universidad del Atlántico, 2000; Carlos Uribe Uribe, Poblamiento y relaciones subregionales en el bajo Magdalena: Brazo de Loba, 1770-1900, Medellín, Tesis de Historia Universidad Nacional, 2002; Francisco Balmaseda, "La feria de Magangué", en Boletín Historial, 45-46, 1919; Orian Jiménez y Edgardo Pérez, La Mojana: medio ambiente y vida material en perspectiva histórica, Medellín, Universidad de Antioquia, 2007. Esta historiografía recalca y conmemora la profusión y el notable servicio que al país le prestaron las "veneradas" ferias, sin hacer un examen serio sobre el mismo. Nuestro interés no gira en torno a este tema, como si lo está el de Cristian Roa Valdelamar en su tesis de pregrado antes citada, por lo tanto no pretendemos hacer un estudio exhaustivo sobre el mismo, ya que nuestro interés es otro.

17 David Peñas Galindo y Oscar Arquez, Espacio, poblamiento y sociedad en la región de la depresión momposina Medellín, Ed. Lealón, 1994; Javier Ocampo, Historia básica de Colombia, Bogotá, Plaza \& Janes Editores, 2007; "La patria Boba", en Cuadernillos de Historia, Bogotá, Panamericana, 1998.

${ }^{18}$ Orlando Fals Borda, Historia doble de la Costa. Mompox y Loba, Bogotá, Universidad Nacional de Colombia, 2002.

${ }^{19}$ Sergio Paolo Solano, Roicer Flórez y William Malkún, "Ordenamiento territorial y conflictos jurisdiccionales en el Bolívar Grande 1800-1886”, en Historia Caribe, 13, 2008, pp. 65-119. En otros de sus artículos señalan el papel prominente que tuvieron los ganaderos y los comerciantes en el Estado Soberano de Bolívar, ver: Sergio Paolo Solano, Roicer Flórez y William Malkún, "Ganaderos y comerciantes: el manejo del poder político en el Estado Soberano de Bolívar (Colombia), 1857-1886", en Historia y Sociedad, 18, 2010, pp.15-42.

${ }^{20}$ S. P. Solano, R. Flórez y W. Malkún, “Ordenamiento territorial”, p.91.
} 
Magangué era un importante punto comercial, debido a la desviación que tuvo el rio Magdalena por el Brazo de Loba e hizo de éste un puerto clave para el comercio, y porque para las compañías de navegación a vapor era más rentable el tráfico por este brazo. Además, ahí, se daban anualmente tres importantes ferias. ${ }^{21}$

Este auge hace que Magangué sea elevado a la categoría de provincia y es ahí cuando van a tomar fuerza los conflictos entre ésta y la de Mompox. ${ }^{22}$ Debido a que, no logran definirse con claridad los limites jurisdiccionales que las separan, y, por un lado, la organización de las provincias, por el otro, la expansión de los hatos ganaderos hicieron que se disputaran los territorios; ya que entre más terrenos se tiene o se acapare, más poder económico y político se va a ejercer en la provincia y para la provincia. Dado que, quien tiene más tierra, tiene más poder. Esto le permitirá a cualquier actor social ejercer un dominio en la provincia y enaltecer el papel de ella ante las demás. Por consiguiente, se van a aumentar y a configurar las disputas y/o conflictos entre estos dos: Magangué y Mompox. Los distritos y las aldeas de cada provincia vivían una lucha semejante por mantener sus categorías y no dejar que los relegaran a una categoría inferior o, por obtener una mayor. En ese orden de ideas, el presente artículo intenta responder los siguientes cuestionamientos: ¿Cómo hicieron las provincias de Magangué y Mompox para soportar los auges o los estancamientos con respecto a la otra? ¿Qué medidas tomaron con respecto a la otra? ¿Qué leyes las amparaban? Y ¿Cómo hicieron sus distritos para mantener sus categorías y las aldeas como lograron alcanzar un status mejor, al momento de las organizaciones $y$ reorganizaciones en el interior de estas dos provincias? ¿De qué se valieron sus actores sociales para que sus poblados mantuvieran sus categorías en el orden territorial de la provincia o para mejorarlos?

De esta manera, pretendemos contribuir en el análisis de la cultura política de los actores sociales que impulsaban dichas rivalidades a nivel local, y como repercutían en la vida pública de las provincias, del estado y de la nación. Para ello, se mirarán las relaciones clientelistas entre los diversos actores sociales influyentes de estas y en los diversos poblados emergentes del sector rural del Estado Soberano de Bolívar, que las conformaban. Estos vínculos permitían conformar unas pequeñas elites en los campos, las que a su vez tenían vínculos regionales y nacionales. ${ }^{23}$

\footnotetext{
${ }^{21}$ C. Roa Valdelamar, Ferias comerciales de Magangué; A. del Valle, Compendio monográfico de la villa, p.77; L. Striffler, El rio san Jorge.

${ }^{22}$ Eloy A. Miranda Gil, Disputas territoriales, políticas y económicas entre las provincias de Magangué y Mompox, 18531875, Cartagena, trabajo de grado para optar al título de historiador, Universidad de Cartagena, 2013.

${ }^{23}$ Por otra parte Hermes Tovar nos ha influenciado a hacer esta investigación puesto que “... la provincia (de Cartagena) como objeto de relaciones sociales y económicas y como red de poblados y ciudades subsidiarias espera aún un esfuerzo minucioso de investigación histórica", ver: Hermes Tovar, "La historiografía sobre Cartagena de indias en el siglo XVIII", en Haroldo Calvo y Adolfo Meisel (eds.), Cartagena de indias y su historia, Cartagena, Universidad Jorge Tadeo Lozano, Seccional Caribe y Banco de la República, 1997. A nosotros nos interesan, más que todo, los desencuentros que habían entre ellas, es decir las relaciones de conflictos que las caracterizaron entre 1853 y 1875 . Y como esos distritos aldeas y cantones pujaban para mantener su categoría u obtener una más alta dentro la provincia.
} 
Nuestro argumento se basa en que el desarrollo de Magangué y el estancamiento de Mompox hizo que se generaran disputas en la subregión momposina $\mathrm{y}$, por otro lado, la organización territorial al interior de las provincias llevó al problema de la disolución de algunos distritos que carecían de los elementos básicos que impuso la provincia y el Estado Soberano para seguir ostentando dicho título y a la emanación de algunas aldeas que por sus características debían obtenerlo. Además, esta organización desencadenó conflictos entre las dos provincias, puesto que, no estaban definidos con claridad los límites jurisdiccionales de ambas. En otras palabras, este trabajo muestra ciertas cosas que no se conocen de la historia política nacional, a nivel local, en donde se hace un análisis comparativo entre dos provincias del Estado Soberano de Bolívar en la segunda parte del siglo XIX: Magangué y Mompox. Y se mira como sus distritos pujaban por mantener sus categorías territoriales.

El artículo tiene la siguiente estructura, en primer lugar, se hará un recorrido por las diversas constituciones que reorganizaron el territorio nacional, estatal y provincial a comienzos del siglo XIX, con el fin de contextualizar como se venían organizando las provincias del Estado Soberano de Bolívar. En segundo lugar, rastreará las vicisitudes de Magangué y de Mompox desde finales del siglo XVIII y comienzos del siglo XIX, con el fin de conocer los auges, los estancamientos y las disputas a las que se enfrentaron estas dos provincias en el transcurso de ese período. Luego de haber hecho ese recorrido pasaremos a mirar, en tercer lugar, como organizaron su territorio las provincias de Magangué y Mompox y los conflictos a los que se enfrentaron.

\section{Breve bosquejo constitucional sobre el ordenamiento territorial en Colombia a comienzos del siglo XIX}

Una vez lograda la independencia total en la Nueva Granada, se empezó por un ordenamiento territorial que se diferenciará del que predominó durante el periodo colonial, el que estaba instituido por los Partidos y los Corregimientos. Este nuevo orden comenzó con una organización basada en el régimen departamental, que a su vez estuvo ordenado en Provincias, Cantones y Parroquias, y predominó la vida provinciana. Entonces el territorio que pertenecía a la antigua provincia de Cartagena pasó a formar parte del Nuevo Departamento del Magdalena, el que tuvo como capital a esa ciudad $^{24}$.

Este ordenamiento se mantuvo casi intacto en las siguientes cartas constitucionales que se promulgaron en la primera mitad del siglo XIX. Por ejemplo, la carta constitucional del 29 de febrero de 1832 determinó que el territorio de la Nueva Granada sería dividido en provincias, cantones y

\footnotetext{
${ }^{24}$ Ver: Javier Ocampo, “Él proceso político, militar y social de la independencia”, en Nueva Historia de Colombia, Bogotá, Planeta, 1989, Tomo II; Diego Uribe, Las constituciones de Colombia, Madrid, Cultura hispánica, 1997; S. P. Solano R. Flórez y W. Malkún, “Ordenamiento territorial”, pp. 65-119.
} 
distritos parroquiales, esta constitución le asignó grandes poderes a las provincias, que de ese modo se consolidaron como las unidades primordiales del ordenamiento territorial, político y administrativo del país; así mismo, la constitución de 1843 ratificó esta división territorial y estableció que cada provincia estaría compuesta por uno o más cantones, y cada Cantón en distritos parroquiales ${ }^{25}$.

Y en la constitución política del 20 de mayo de 1853 - la que daría vida al periodo de la federación en Colombia- se estableció que el territorio de la República colombiana seguiría dividido en provincias para los efectos de la administración general de los negocios nacionales, y estas, a su vez, en distritos parroquiales, eliminando así el régimen cantonal que había sido creado en 1824, -aunque algunas de ellas conservaron el Cantón como unidad territorial entre la provincia y el distrito y otras previeron una unidad mucho menor que el distrito: las aldeas.

Ahora bien, gracias a estas constituciones nacionales $(1832,1843$ y 1853$)$ las provincias mantuvieron relaciones directas con el Estado central. Y la última de ellas (1853) entregó facultades a las provincias para que se dotaran de sus propias constituciones, tal como lo hicieron las treinta y seis existentes entre 1853 y 1856, con un total de sesenta y una constituciones emanadas en ese lapso de tiempo ${ }^{26}$. Así fue como las provincias del Bolívar Grande empezaron a ganar autonomía con respecto a la ciudad Heroica: proclamando sus propias constituciones ${ }^{27}$.

De esta manera, podemos ver el trasegar constitucional de Colombia a principios del siglo XIX que a través de estas cartas buscó reorganizar política, administrativa y territorialmente al recién creado país. Ello con el fin de dejar a un lado las herencias coloniales bajo las cuales estaba organizado el territorio; aunque, de alguna manera, no se abandonaron del todo, ya que se ciñeron a la forma que había establecido la colonia, esto es, a la manera como se había poblado y/o repoblado el territorio ${ }^{28}$. Éstas "reorganizaciones", muchas veces, fueron de manera forzada, lo que hizo que se dieran enfrentamientos sociales en las zonas rurales de las provincias. Además, en ese reordenamiento se inmiscuyeron las medidas del ordenamiento político y

\footnotetext{
${ }^{25}$ Diego Uribe, Las constituciones de Colombia; Carlos Restrepo, Constituciones de la primera república liberal, 18531856, Bogotá, Universidad Externado de Colombia, 1979; Miguel Borja, Estado, sociedad y ordenamiento territorial en Colombia, Bogotá, CEREC/Universidad Nacional, 2000; David Bushnell, Una nación a pesar de sí misma, Bogotá, Planeta, 2007, pp. 86, 130, 145-146 y 161-164; Edwin Cruz, "El federalismo en la historiografía política colombiana (1853-1886)", en Historia Crítica, 44, 2011, p. 104-124, pp. 105.

${ }^{26}$ Álvaro Tirado, Descentralización y centralismo en Colombia, Bogotá, Fundación Friedrich Newman-Oveja Negra, 1983, pp. 43; C. Restrepo, Constituciones de la primera república liberal, 1853-1856.

${ }^{27}$ C. Restrepo, Constituciones de la primera república liberal; S. P. Solano, R. Flórez y W. Malkún, "Ordenamiento territorial".

${ }^{28}$ Poblaciones y/o repoblaciones impulsadas por la corona española a lo largo del siglo XVIII como medida para volver a "tomar el poder" que había perdido en sus colonias a ultramar. Medidas llevadas a cabo por Antonio de la Torre y Miranda en la provincia de Cartagena. Véase: Jorge Conde, Espacio, Sociedad y Conflictos en la provincia de Cartagena 17401815, Barranquilla, eds. Universidad del Atlántico, pp. 55-85; "Reformas Borbónicas y reordenamiento del espacio en el Nuevo Reino de Granada. El caso de la provincia de Cartagena”, en Historia Caribe, 1, 1995, pp. 5-24; Wilson Blanco, Historia del Carmen de Bolívar y su tabaco en los Montes de María. Siglos XVIII-XX, Cartagena, Universidad de Cartagena, 2009, pp. 51-69.
} 
administrativo estatuido por las diferentes legislaciones del país, las del Estado de Bolívar y el departamento del mismo nombre.

\section{Magangué y Mompox: decadencias, auges y disputas}

Mompox durante el periodo colonial tuvo una gran prosperidad gracias a que, contaba con una gran actividad económica y comercial por ser uno de los puertos intermedios sobre el rio magdalena, entre el interior del país y el norte del virreinato de la Nueva Granada, aunado a esto contaba, por un lado, la cría de ganado, y, por el otro, estratégico desde el punto de vista militar. Además, era el lugar predilecto donde se ejercía la práctica del contrabando desmesuradamente, ya que tenía un vasto territorio disperso poblacionalmente y, además, era el punto de confluencia de diferentes ríos que facilitaban el ejercicio de éste. Factores que hicieron que se convirtiera su confiscación en algo casi imposible para la administración colonial, pero cuando esto se lograba, generaba ingresos al tesoro real. Todo ello conllevó a que su elite acumulara grandes fortunas y que fuera nombrado provincia entre 1774 y 1777 . Además, dada su importancia económico-política este fue el centro urbano que tuvo los mayores enfrentamientos con Cartagena. ${ }^{29}$

En el periodo republicano, Mompox tenía cierta hegemonía en el territorio estatal, junto a Cartagena. Mompox fue erigida departamento en la constitución de 1812, luego en 1824 fue nombrada cantón y en 1826 volvió a obtener la categoría de provincia ${ }^{30}$. El siguiente grabado da una imagen perentoria del auge económico y comercial que vivía la villa momposina a comienzos del siglo XIX. En donde se aprecian bogas, pescadores, sirvientes, caballeros y una que otra dama de la ciudad en el juego comercial del mercado de la villa.

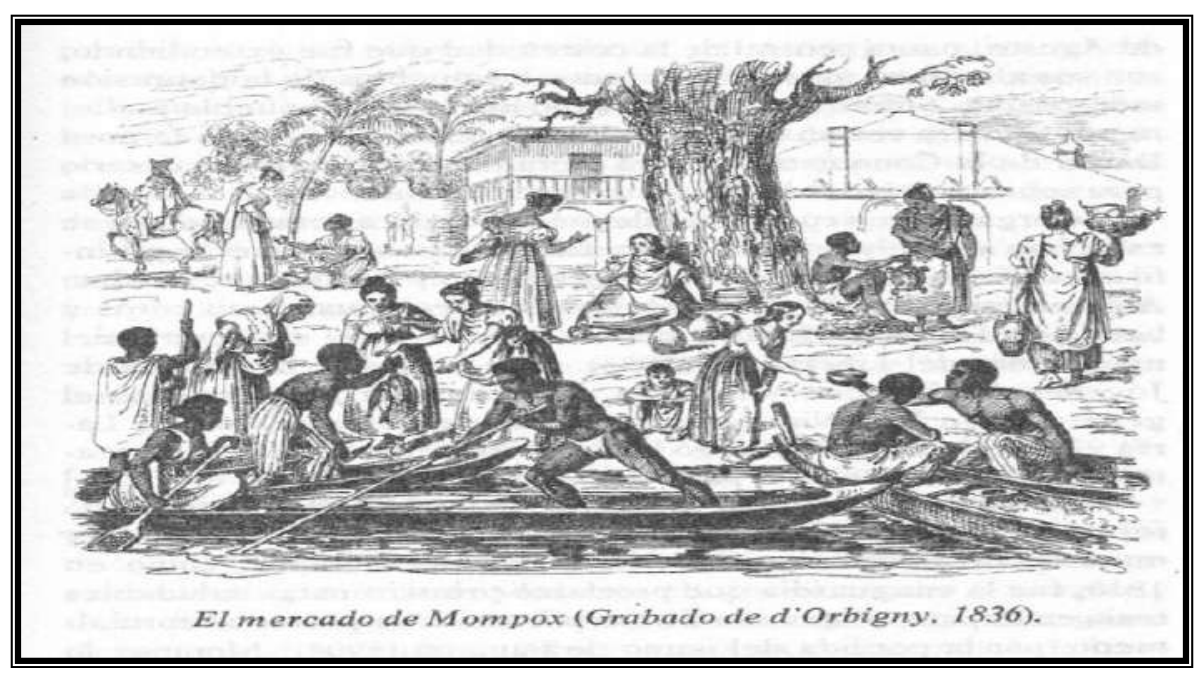

\footnotetext{
${ }^{29}$ Muriel Laurent, El contrabando en Colombia en el siglo XIX. Prácticas y discursos de resistencia y reproducción, Bogotá, Universidad de los Andes, 2008; J. Conde, Espacio, Sociedad y Conflictos, pp. 29-33; S. P. Solano, R. Flórez y W. Malkún, “Ordenamiento territorial”, pp. 60, 78, 94 y 102; Orlando Fals Borda. Mompóx y Loba, Bogotá, Carlos Valencia Editores, 1980, pp. 123B-125B.

${ }^{30}$ S. P. Solano, R. Flórez y W. Malkún, “Ordenamiento territorial”, pp. 66-68, 82-83.
} 
Empero, esta ciudad comienza a tener cierta decadencia económica por lo dilatado de su territorio y su condición de reciente colonización, esto hizo que posteriormente Magangué se separara de ella ${ }^{31}$. Pedro Salzedo del Vilar en sus apuntaciones historiales de Mompox, señala como principales causas de la crisis de la ciudad valerosa las siguientes: la desviación del cauce del rio Magdalena; la intromisión de la navegación a vapor; decadencia del comercio; el desguarnecimiento de las fuerzas militares y la migración de los momposinos hacia otras ciudades (en consecuencia su población va a sufrir un proceso de estancamiento, ver cuadros 1, 2, 3 y 5). Esta migración la explica Salzedo del Vilar de la forma que sigue a continuación:

...Se inició el éxodo de familias enteras desde 1860, aduciéndose, con razón aditiva, los pésimos efectos de las guerras civiles. A Bogotá, Cartagena, Santa Marta, Popayán, y a la naciente Barranquilla, se dirigieron muchos compatriotas. A Paris, Nueva York y otras ciudades del exterior migraron otros en busca de la paz y del sosiego que aquí no reinaba ${ }^{32}$.

Las guerras civiles de que habla del Vilar eran las que reinaban en ese tiempo en todo el país debido al conflicto que empezó Nieto contra Calvo en Cartagena. ${ }^{33}$ Pero, Mompox, antes que se empezara esta guerra civil, en años precedentes había sufrido el azote de varias discordias internas (1855-1858) ${ }^{34}$. A consecuencia de estas guerras va a aumentar la crisis de la ciudad.

Cuadro 1: Población de Mompox 1778-1851

\begin{tabular}{|c|c|}
\hline Años & Población \\
\hline 1778 & 6978 \\
\hline 1835 & 8067 \\
\hline 1843 & 7919 \\
\hline 1851 & 7336 \\
\hline
\end{tabular}

Fuente: Adolfo Meisel, "Esclavitud, mestizaje y hacienda en la provincia de Cartagena 1533-1851”, en El Caribe Colombiano, Barranquilla, Uninorte, 1988, p. 136.

El gobernador de la provincia, Julián Berrío, en su informe de 1862 menciona algunas de estas causas, a saber: la perdida de ciudadanos en la guerras, incendios consecutivos, etc., además,

...Han sobrevenido otras causas por la naturaleza. La gran creciente del Magdalena i sus afluentes, en Mayo del año próximo pasado causó muchísimos estragos en los ganados i las sementeras, [sic.] i destruyó muchas casas en el barrio de San Francisco de esta ciudad ${ }^{35}$.

\footnotetext{
${ }^{31}$ J. Conde. Espacio, Sociedad y Conflictos, pp. 37 y 108; S. P. Solano, R. Flórez y W. Malkún, "Ordenamiento territorial", pp. 93-94.

${ }^{32}$ Pedro Salzedo del Vilar, Apuntaciones historiales de Mompox, Mompox, Tip. Democracia, 1938.

${ }^{33}$ O. Fals, El Presidente Nieto.

${ }^{34}$ Archivo Histórico de Cartagena (AHC), "Informe del Gobernador de la provincia de Mompos conforme lo previene el inciso 29 del art. $7^{\circ}$ de la lei de réjimen político", en Gaceta del Estado Soberano de Bolívar, Cartajena, 5 de octubre de 1862.

${ }^{35} \mathrm{AHC}$, "Informe del Gobernador de la provincia de Mompos conforme lo previene el inciso 29 del art. $7^{\circ}$ de la lei de réjimen político", en Gaceta del Estado Soberano de Bolivar, Cartajena, 5 de octubre de 1862.
} 
Las anteriores fueron algunas de las causas de la crisis de Mompox, por lo que se le concede un año de inmunidad a la ciudad en 1862 con el fin de que logre recuperarse económicamente. Es decir, no contribuirá con los impuestos del Estado, los cuales invertirá en beneficio propio ${ }^{36}$.

Cuadro 2: Población de la provincia de Mompox 1851-1870

\begin{tabular}{|c|c|}
\hline Año & Población \\
\hline 1851 & 22.701 \\
\hline 1870 & 22.499 \\
\hline
\end{tabular}

Fuente: Biblioteca Luis Ángel Arango (BLAA), Estadística general de la Nueva Granada 1848-1870, Población e instituciones parte segunda; Gaceta de Bolívar, Cartagena, 5 de febrero y 9 de mayo de 1871; AHC. Fondo gobernación (manuscritos), Sección distritos y municipios, Legajo n ${ }^{\circ}$ 3, Años 1842-1865.

Magangué, por su parte, desde que fue reorganizada por Antonio de la Torre y Miranda en su cuarta salida realizada el 28 de octubre de $1776^{37}$, comenzó a florecer y empezó a desplazar a Mompox como centro portuario de intercambio comercial en esa zona, así como lo arguye Jorge Conde:

Esta población [Magangué] mostraba cierta importancia portuaria y comenzaba a rivalizar con su vecina, la villa de Mompox, porque sirve de escala a todos los que comercian en las minas de oro de las jurisdicciones de Nechí, Zaragoza, Guamocó y Cáceres, y a los que siguen - por aquella parte- a la provincia de Antioquia, precisándolos a detenerse para fletar embarcaciones en que conducir sus géneros y herramientas y demás útiles para los trabajos de aquellas minas, y también ganados, aves menstras y otros frutos necesarios para su subsistencia y negociaciones... ${ }^{38}$.

Lo anterior demuestra el cierto auge que venía tomando este punto comercial desde el periodo colonial, por consiguiente, tuvo que enfrentarse al poder que ejerció Mompox en esa zona, puesto que la elite Momposina pugnaba para desmoronar o para que al menos se estancara dicho crecimiento. Pero era tal la fuerza del crecimiento económico-político de Magangué lo que hizo que en el período republicano adquiriera la categoría de cabecera de cantón con jurisdicción sobre Guazo, Retiro, San Sebastián, Tacasaluma y Yatí; posteriormente se quiso crear la provincia del San Jorge con cabecera en ella pero fue abolida por oposición de los Momposinos ${ }^{39}$.

Al mismo tiempo se vieron envueltas en un conflicto de más de 90 folios, en donde "Ignacio Sánchez Mora, corregidor i capitán aguerra de Magangué, se queja contra el cabildo de Mompox, que desconociéndole el cargo de que estaba investido, quiso disminuirle su jurisdicción en varios territorios". El caso lo terminó ganando el cabildo de la villa de Mompox gracias a su mayor

\footnotetext{
${ }^{36}$ AHC, Gaceta del Estado Soberano de Bolívar, Cartagena, 11 de enero de 1863

${ }^{37}$ J. Conde, espacio, Sociedad y Conflictos, p. 74.

${ }^{38}$ J. Conde, Espacio, Sociedad y Conflictos, p. 81

${ }^{39}$ S. P. Solano R. Flórez y W. Malkún, “Ordenamiento territorial”, pp. 94-95.
} 
poderío e influencia económico-política que ejercía, en ese entonces, sobre las autoridades estatales y sobre esta subregión ${ }^{40}$.

En este punto debemos preguntarnos ¿a qué se debió este estancamiento de la villa de Mompox y el paralelo auge de Magangué? Fabio Zambrano, en su trabajo sobre la ciudad y el territorio, donde analiza el proceso de poblamiento en Colombia, puede arrojarnos algunas luces que nos permitirán resolver dicha problemática, pues bien, él plantea que a principios de este siglo:

El orden geográfico urbano basado en el principio de ciudades, villas y parroquias establecido en la colonia, se mantuvo durante los primeros años de independencia, lo que se puso de manifiesto después de las guerras de independencia era que no todos los centros urbanos quedarían en igual condición, por el contrario, el viejo orden se mantuvo hasta la República. ${ }^{41}$

Esto nos ayuda a comprender la crisis política en la que quedó sumergida la provincia de Cartagena, que después de las guerras de independencia se muestra a través de las viejas rivalidades, como las de Mompox contra Cartagena, y las nuevas rivalidades, aunque no tan nuevas, como la de Mompox y Magangué, buscando romper el viejo principio impuesto desde la colonia respecto al ya mencionado orden urbano con relación a los privilegios que ostentaba la ciudad. Es decir, que como al momento en que se da el triunfo de la República “...los sistemas de privilegios concedidos por el régimen colonial a ciertas poblaciones 2 desaparecieron, comienzan a acrecentarse los conflictos; ya que estos estuvieron encarnados “... en los centros urbanos emergentes que empezaron a disputar el protagonismo económico, político, jurisdiccional y territorial que disfrutaban aquellas poblaciones..."42.

Cuadro 3: Población de Magangué y Mompox 1851-1870

\begin{tabular}{|c|c|c|c|c|c|c|}
\hline $\begin{array}{c}\text { Nombre } \\
\text { lugares }\end{array}$ & $\begin{array}{c}\text { Población } \\
\mathbf{1 8 5 1}\end{array}$ & $\begin{array}{c}\text { Población } \\
\mathbf{1 8 5 9}\end{array}$ & $\begin{array}{c}\text { Población } \\
\mathbf{1 8 6 0}\end{array}$ & $\begin{array}{c}\text { Población } \\
\mathbf{1 8 6 5}\end{array}$ & $\begin{array}{c}\text { Población } \\
\mathbf{1 8 7 0}\end{array}$ & $\begin{array}{c}\text { Incre } \\
\text { mento }\end{array}$ \\
\hline Magangué & 8600 & 13.611 & 13.237 & 12.713 & 16.946 & $97 \%$ \\
\hline Mompox & 22.701 & 21.546 & 17.342 & 18.991 & 22.499 & $-0.88 \%$ \\
\hline
\end{tabular}

Fuente: BLAA, Estadística general de la Nueva Granada1848-1870; BBC, Gaceta Oficial del Estado de Bolívar, Cartagena, octubre 9 de 1859; BBC, Gaceta Oficial del Estado de Bolivar, Cartagena, marzo 7 de 1860; BBC, Gaceta Oficial del Estado Soberano de Bolívar, Cartagena, mayo 7 de 1865; Gaceta de Bolívar, Cartagena, 5 de febrero y 9 de mayo de 1871.

Este protagonismo lo adquirían debido a “... el despegue de una actividad económica..." el cual hacia que migraran a las ciudades, grandes “...flujos de pobladores..." que le permitían “... contar con unas bases gravables

\footnotetext{
${ }^{40}$ Archivo General de Nación (AGN), Sección I, Fondo Cabildo, legajo n ${ }^{\circ}$ 8. Citado por J. Conde. espacio, Sociedad y Conflictos, p. 108; S. P. Solano R. Flórez y W. Malkún, "Ordenamiento territorial”, p. 79.

${ }^{41}$ Fabio Zambrano, Ciudad y territorio. El proceso de poblamiento en Colombia, Bogotá, Academia Colombiana de Historia/Instituto francés de Estudios Andinos, 1993.

42. P. Solano R. Flórez y W. Malkún, “Ordenamiento territorial”, pp. 67, 70 y 90; L. D. Calvo, Juan José Nieto. Regionalismo y Poder, p. 25; J. Conde, espacio, Sociedad y Conflictos, pp. 91-92; Germán Colmenares, "La economía y la sociedad coloniales. 1550-1800”, en Nueva Historia de Colombia, Bogotá, Planeta, 1989, Tomo I, pp. 121.
} 
significativas, garantía para que las comarcas bajo su influencia cumplieran con los requisitos establecidos por las leyes para ser erigidas en cantones o provincias" 43 . O sea, que estos conflictos tuvieron como trasfondo un problema de tipo económico, en consecuencia, se pasan a un segundo plano las condiciones políticas como argumento para ser reconocidas como una unidad administrativa superior a la que se encontraba, verbigracia en una provincia como sucedió en nuestro caso con Magangué.

Aunque de nada servía contar con el despegue de alguna actividad económica, si no se estaba articulado con el ordenamiento exportador de la época o en la distribución interregional, así como nos lo hace saber Juan Felipe Gutiérrez cuando afirma que: “... la dinámica económica y demográfica es mayor en los centros urbanos que están insertos en el esquema del comercio exportadorimportador". En fin, algunas ciudades luego de pasar su auge “... debieron competir con ciudades nuevas que se articulaban a las nuevas dinámicas del territorio, y que, finalmente se convirtieron en su negación cuando no en su anulación"44. Al respecto Fernand Braudel puntualiza que,

En la ciudad, en el mercado central, los intercambios tienen otra dimensión. Allí llegan mercancías y víveres de los pueblos. Pero la ciudad, a su vez, está relacionada con otras ciudades que la rodean o la dominan. La ciudad es el elemento que comienza a ser francamente extraño a la economía local, que sale de su estrecho marco y se relaciona con el vasto movimiento del mundo, que recibe mercancías exóticas, preciosas, desconocidas en el lugar, y las distribuye entre los mercados y tiendas inferiores ${ }^{45}$.

Pues bien, como hemos señalado anteriormente, Magangué empieza a relegar a Mompox a un segundo plano en esta zona, debido a que se empezaba a articular a este orden comercial $^{46}$, gracias a que, como lo advierte Juan José Nieto gobernador del Estado Soberano de Bolívar en 1858, era un importante punto comercial, debido a la desviación que tuvo el Rio Magdalena por el Brazo de Loba e hizo de éste un puerto clave para el comercio, puesto que para las compañías de navegación a vapor era más rentable el tráfico por este brazo $^{47}$.

\footnotetext{
${ }^{43}$ S. P. Solano R. Flórez y W. Malkún, “Ordenamiento territorial”, pp. 85; Juan José Nieto, Geografía histórica, estadística y local de la provincia de Cartagena, república de la Nueva Granada descrita por cantones, Cartagena, 1839, pp. 108-218. En este periodo, la población de Magangué se va a multiplicar casi al 100\%, mientras que, la de Mompox va a tener una tendencia a la baja (ver cuadros 3 y 5 ).

${ }^{44}$ Juan F. Gutiérrez, "Transportes y ocupación del territorio en Colombia", en Diana Ceballos (ed.) Prácticas, territorios y representaciones en Colombia, 1849-1960, Medellín, Universidad Nacional, 2009, pp. 95 y 81.

${ }^{45}$ Fernand Braudel, "Los juegos del intercambio", en Civilización material, economía y capitalismo, siglos XV-XVIII, Tomo II, Madrid, Alianza Editorial, 1984.

${ }^{46}$ Aunque en esa dinámica ambas ciudades cumplían con el papel de puertos de apoyo y distribución. Ver: F. Braudel, "Los juegos del intercambio"; J. F. Gutiérrez, "Transportes y ocupación del territorio en Colombia", pp. 95. Ya que "todos los vapores que subían y bajaban por el magdalena se detenían en Magangué, desde donde la carga se distribuía en pequeños botes, canoas y mulas..." con destino “.... las sabanas de Bolívar y a los valles adyacentes del San Jorge, bajo Cauca y Nechí”. Es decir Magangué servía como centro de acopio y de intercambio en esa subregión y de enlace entre los puertos marítimos y el interior, tarea que en antaño se ocupaba su vecina, la villa momposina. Ver: E. Posada. El Caribe colombiano, pp. 267-268; S. P. Solano, R. Flórez y W. Malkún, “Ordenamiento territorial”, pp. 95.

${ }^{47}$ AHC. "Mensaje del gobernador del Estado de Bolívar, a la asamblea legislativa en sus sesiones ordinarias de 1858", en Gaceta Oficial del Estado de Bolívar, Cartagena, Octubre $1^{\circ}$ de 1858.
} 
De dicha desviación también se manifestó Felipe Pérez cuando hizo su viaje por el Rio Magdalena en 1864, señalando que había hecho su recorrido, en esta subregión, “...por el brazo de Loba, que presenta menos inconvenientes para una navegación rápida, tanto por la profundidad de su cauce, como por la completa ausencia de palos y otros obstáculos", que presentaba el Brazo de Mompox; por consiguiente visitó Magangué e hizo una breve descripción de la capital de dicha provincia en ese periodo, en su argumento señalaba,

Empero, si no vimos la ciudad valerosa, vimos a Magangué, célebre por sus ferias y notable por su bello y pintoresco caserío, que es de calicanto, con anchas azoteas y que está tendido sobre la alta riba del rio, como un tapiz otomano. El sol iba a ponerse, y sus rayos de oro [...] daban al lugar toda la poesía del crepúsculo y toda la hermosura de una ciudad del Egipto $^{48}$.

Por otro lado, y sumado a la importancia como centro de acopio y de intercambio comercial y a la desviación que presentó el rio magdalena por el Brazo de Loba $-\mathrm{y}$ pese a los esfuerzos que hicieron los Momposinos para detenerla $^{49}$, Magangué se siguió fortaleciendo, además, por las ferias comerciales que anualmente tenían lugar ahí, y que para 1869 aumentarían a tres por año ${ }^{50}$. Manuel María Madiedo, en un pasaje de su novela titulada Nuestro siglo XIX, ofrece un detallado cuadro de las mismas:

Es necesario dar de paso una idea de lo que es una feria de Magangué, para tenerla completa luego del teatro que nuestro joven iba a explotar... Magangué cuenta hoy (1868) dos ferias: una en febrero y otra en junio [...] Como la población es pequeña y la concurrencia numerosa, pues allí se aparecen hombres de todos los puntos de la Nueva Granada y aún del extranjero, se hace preciso solicitar una casa de antemano pagándola a un precio enorme. A medida que se acerca el día designado afluyen las embarcaciones: el puerto se cubre de numerosísimos enjambres de piraguas, barquetas, bongos, botes de mar y champanes de todos los tamaños... ${ }^{51}$.

El gobernador de Magangué, en su informe de 1869 sobre la marcha de la administración pública de la provincia, nos muestra como en “... las ferias que tienen lugar tres veces al año en la capital, entonces circulan grandes

\footnotetext{
${ }^{48}$ Felipe Pérez, Episodios de un viaje (1864/5), Bogotá, Editorial ABC/Ministerio de Educación de Colombia, 1946, pp. 41. ${ }^{49}$ Orlando Fals, El Presidente Nieto. Bogotá, coed, Universidad Nacional/Banco de la República/El Áncora Editores, 2002 , pp. 52a. Ahí se puede leer: "la cámara provincial [de Mompox] nombró una junta patriótica para hacer una estacada rellena de piedras, y represas en la boca de Loba al pie de el Banco y en los brazos de orejero y Lugo...", para tratar de evitar que el rio se desviara. Por otro lado, ver: BBC. Gaceta de Bolívar. Cartagena, 25 de marzo de 1866. En donde nos damos cuenta que el gobernador Juan Castellanos acompaña a unos ingenieros a hacer un examen del rio Magdalena en la boca de Loba “... para determinar la clase de trabajos que han de ejecutarse, con el fin de dirijir por su cauce primitivo las aguas de dicho rio...". Esta desviación también pudo haber sido provocada por los magangueleños y por uno de los hacendados de Mompox que tenía sus intereses en las tierras de Loba y al cual le interesaba tener más agua frente a ellas. Véase: O. Fals, El Presidente Nieto, pp. 52A.

${ }^{50}$ AHC. Gaceta de Bolívar, Cartagena, Septiembre 12 de 1869; C. Roa, Ferias comerciales de Magangué (1858-1902); A. Del Valle, Compendio monográfico de la villa de Magangué, pp.77; L. Striffler, El rio San Jorge; E. Posada, El Caribe colombiano. Una historia regional, pp. 267-268; Aquileo Parra, Memorias (1825-1875), Bogotá, Editorial Incunables, 1982. Un análisis reciente de estas ferias se puede ver en la monografía de J. F. Meneses, Presencia e influencia italiana en Colombia: El caso de Magangué, pp. 123-135, en donde se aprecian las repercusiones que trajeron estas ferias al crecimiento y desarrollo de la ciudad.

${ }^{51}$ Manuel María Madiedo, Nuestro siglo XIX, Bogotá, Imprenta de Nicolás Pontón, 1868, pp. 239-241.
} 
capitales i se verifican importantes transacciones mercantiles. En estas ferias se transforma el país como por encanto, de manera que el transeúnte que ocasionalmente concurre a ella, i ve este emporio, se forma la mas halagüeña idea del país..."52.

Las ferias jugaron un papel importante en la región dado que permitían la dinamización del comercio a nivel local, regional y nacional, en donde se integraban en ese juego comercial desde el gran comerciante hasta el más humilde negociante ${ }^{53}$. Por ello, fue que Juan José Nieto en su mensaje a la Asamblea en 1858 solicitaba que se le dieran “...una protección mas inmediata i activa [...] para que las contribuciones que allí se causen se hagan más productivas de lo que hoi lo son" 54 .

Protección que se hizo muy estricta en 1860 por el gobernador de Magangué, ya que se sospechaba que los vecinos de Mompox fueran a tomar represalias contra Magangué, atentando contra su principal fuente de crecimiento, las ferias comerciales. Esto se nota en una carta enviada a la secretaria del Estado por el gobernador de la provincia de Magangué, Rafael González, quien informa lo transcurrido en la feria de 1860, así:

...hace notado que sim embargo de la gran concurrencia de jentes que de diferentes puntos han concurrido ha pasar la feria de junio ha concluido esta, sin que se haya presentado el menor desorden, esto mizmo hizo que hubiese buena dispociciones por parte de los concurrentes para entregarse con tranquilidad a toda clase de transacciones en el variado mercado: siendo lo más notable que ni siquiera una riña en que hubiese resultado herida [la feria], cuando esto con razon se temía por la reunión de tantos Momposinos que tan mal se quieren elloz mismos. ${ }^{55}$

Mientras Magangué iba consolidando su auge con dichas ferias comerciales, Mompox va a seguir su proceso de estancamiento al cual contribuyó la guerra en la que estaba la nación por esos tiempos, entre otras causas, como las que señala el gobernador de la provincia en 1862:

La serie de combates que acabo de apuntar a la lijera con el esclusivo objeto de que se tenga una idea de lo que ha sufrido esta población, no ha podido ménos que causar graves quebrantos a esta provincia, muchos de sus hijos han perecido; otros se hallan prisioneros en Antioquia; el comercio se ha paralizado i sus recursos pecuniarios han sufrido menoscabos enormes.

\footnotetext{
52 AHC. Gaceta de Bolívar, Cartagena, Septiembre 12 de 1869.

${ }^{53}$ Ver: E. Posada, El Caribe colombiano, p. 257. En ese orden de ideas, Fernand Braudel advierte que el principal papel de la ferias "consiste en romper el círculo demasiado reducido de los intercambios ordinarios". Véase: Fernand Braudel, "Los juegos del intercambio", en Civilización material, economía y capitalismo, siglos XV-XVIII, Madrid, Alianza Editorial, 1984, Tomo II, p. 58

${ }^{54}$ AHC. "Mensaje del gobernador del Estado de Bolívar, a la asamblea legislativa en sus sesiones ordinarias de 1858", en Gaceta Oficial del Estado de Bolívar, Cartagena, Octubre $1^{\circ}$ de 1858.

${ }^{55}$ AHC, Manuscritos, Fondo gobernación, Sección provincias, Caja n 38, Años 1857-1880.
} 
Por consiguiente el movimiento industrial es casi nulo i ha venido a empeorar la situación la baja de los precios en New York de los productos que se exportan de esta provincia. ${ }^{56}$

Según la cita anterior se puede distinguir, claramente, otro factor esencial proveniente de la guerra entre las causas que generaron el estancamiento de la provincia de Mompox: la baja de precios en New York de productos como la Ipecacuana, el bálsamo de copaiba, la tagua, los palos tinte, la platería, etc. A ello se le sumó que el río continuaba en pésimas condiciones así como lo señaló el mismo gobernador de la provincia, Francisco de P. Ribón en 1867, quien se quejaba porque "el brazo del Magdalena que pasa por esta ciudad continúa en mal estado porque hasta la fecha no ha sido posible emprender los trabajos de canalización". Hechos estos que llevaron a concluir a dicho gobernador lo siguiente:

La industria no ha avanzado un paso. La navegacion por vapor i la facilidad de comunicaciones con el extranjero ha quitado a esta ciudad su importancia mercantil, i algunos capitales se han retirado para buscar plazas mas estensas para sus especulaciones. La gran masa de artesanos de esta capital también ha sufrido mucho con las introducciones de artefactos estranjeros. Lo dicho parecerá una herejía contra los principios económicos; pero el hecho existe i será preciso el transcurso de algunos años para que organizándose de otra manera los ramos de industria en la provincia, mejore la situacion con algunas ventajas.

Pero a pesar de este panorama tan desolador todo no está perdido para la capital de esa provincia, en particular, y para la misma provincia, en general. Dado que, para el gobernador, Mompox podía sobrevivir a todas esas desavenencias debido a que:

...se basta a sí mismo, porque tiene su vida propia en los pueblos circunvecinos. La pesca es abundantísima, las pintorescas laderas de Margarita forman un dilatado plantel en que se producen los más esquisitos frutos de la zona intertropical, i la feracidad de los otros pueblos adyacentes es tal, que vasta para surtir de granos i de otros víveres a todos los pueblos del alto i bajo Magdalena. ${ }^{57}$

Hasta allí nos pudimos dar cuenta de los auges, los estancamientos y las disputas que tuvieron estas provincias; pasemos ahora a ver como organizaron el territorio y los problemas a los que se enfrentaron al momento de efectuar tal organización.

\footnotetext{
${ }^{56} \mathrm{AHC}$, "Informe del Gobernador de la provincia de Mompos conforme lo previene el inciso 29 del art. $7^{\circ}$ de la lei de réjimen político", en Gaceta del Estado Soberano de Bolívar, Cartagena, 5 de octubre de 1862. Seis años más tarde el gobernador de la provincia, Fernando Sánchez, manifestaba la misma situación en su informe. Ver: Biblioteca Bartolomé Calvo (BBC), Gaceta de Bolívar, Cartagena, 17 de septiembre de 1868.

${ }^{57} \mathrm{AHC}$, "Informe anual del Gobernador de la provincia de Mompox", en Gaceta de Bolívar, Cartagena, 31 de Agosto de 1867.
} 


\section{Organización territorial de las provincias de Magangué y Mompox, 1853-1875: Entre distritos y aldeas}
La elevación al rango de distrito de poblaciones que carecen de elementos para sostenerlo, es el descredito de las instituciones federales ${ }^{58}$. ...El pobre no tiene derecho porque no tiene dinero ${ }^{59}$

Las anteriores citas son el resumen de los problemas que vamos a encontrar en esta segunda parte de este capítulo. Es decir, las dificultades con que se encontraron las administraciones provinciales cuando intentaron organizar y reorganizar las provincias de su mando. En otras palabras, mostraremos la organización de las provincias de Magangué y Mompox y los problemas que subyacían tales organizaciones.

Siguiendo los parámetros establecidos en la carta constitucional de 1853, podemos ver en el censo levantado por el prefecto de Mompox que este departamento estaba organizado de la siguiente manera: Distritos, Aldeas, Secciones, etc. Entre los Distritos encontramos a: Mompox, Loba, Hatillo, Simití, Margarita, Magangué, Sucre, Majagual, Achí, Boyacá. Entre las aldeas encontramos: Palomino, San Fernando, Talaigua, Caño Negro los que estaban bajo jurisdicción del distrito de Mompox; Barranco, que pertenecía al distrito de Loba; Morales, Norosí, Rio viejo, San Pablo los cuales estaban bajo jurisdicción del distrito de Simití; Yatí, Guazo, Retiro, San Sebastián, al de Magangué; Tacasaluma, al de Sucre; Palmarito al de Majagual; etc. Y, por último, aparecen varias secciones: Menchiquejo, Guataca, Piñones, que estaban agregados a la aldea de Caño Negro en el distrito de Mompos; el Peñón adscrito a la aldea del Barranco en el distrito de Loba.

En total para ese momento existían diez Distritos, 16 Aldeas y ocho Secciones (cuadro 4). "Las aldeas i secciones que siguen á cada distrito hacen parte de él..."60. Cabe mencionar que en el cuadro del censo encontrado, solo había claridad sobre los nombres de quince Aldeas y de siete secciones, puesto que el material en una parte estaba deteriorado.

Además, en dicho censo del 16 de Octubre de 1857 -del departamento de Mompos al que aún en dicha fecha estaba adscrito Magangué como distritose aprecia que podían haber distritos que no tenían aldeas, otros que no tenían aldeas pero si secciones y otros que no tenían ni aldeas ni secciones, o no estaban censadas.

\footnotetext{
${ }^{58}$ AHC, "Informe del gobernador de la provincia de Mompox", en Gaceta de Bolívar, Cartagena 27 de Agosto de 1868. Cursivas nuestras.

${ }^{59}$ AHC, "Informe anual del gobernador de la provincia de Magangué", en Diario de Bolívar, Cartagena, 6 de octubre de 1875.

${ }^{60}$ AHC, manuscritos, Fondo gobernación, Sección distritos y municipios, Legajo n 13 , Años 1842-1865.
} 
Cuadro 4: De los Distritos, Aldeas y Secciones del Departamento de Mompox; i la población de cada uno de conf ${ }^{\mathrm{e}}$. Al ult ${ }^{\circ}$ (ultimo) censo. 16 de octubre de 1857

\begin{tabular}{|c|c|c|c|}
\hline Distritos & Aldeas & Secciones & Población \\
\hline \multirow[t]{8}{*}{ Mompox } & & & 7336 hab. \\
\hline & Palomino & & 526 \\
\hline & San Fernando & & 714 \\
\hline & Talaigua & & 774 \\
\hline & Caño Negro & & \\
\hline & & Menchiquejo & \\
\hline & & Guataca & \\
\hline & & Piñones & \\
\hline \multirow[t]{3}{*}{ Loba } & & & 1039 \\
\hline & Barranco & & 1036 \\
\hline & & Peñón & \\
\hline \multirow[t]{2}{*}{ Hatillo } & & & 459 \\
\hline & & Ribona & \\
\hline \multirow[t]{5}{*}{ Simití } & & & 1980 \\
\hline & Morales & & 1094 \\
\hline & Norosí & & 324 \\
\hline & Rio viejo & & 806 \\
\hline & San Pablo & & 233 \\
\hline \multirow[t]{3}{*}{ Margarita } & & & 1827 \\
\hline & & Sandoval & \\
\hline & & Chilloa & \\
\hline \multirow[t]{5}{*}{ Magangué } & & & 2512 \\
\hline & Yatí & & 547 \\
\hline & Guazo & & 440 \\
\hline & Retiro & & 761 \\
\hline & San Sebastián & & 338 \\
\hline \multirow[t]{2}{*}{ Sucre } & & & Deteriorado \\
\hline & Tacasaluma & & Deteriorado \\
\hline \multirow[t]{2}{*}{ Majagual } & & & 2409 \\
\hline & Palmarito & & 989 \\
\hline Achí & & & 1002 \\
\hline Boyacá & & & 827 \\
\hline \multicolumn{4}{|c|}{ Totales } \\
\hline 10 & 16 & 8 & 30207 \\
\hline
\end{tabular}

Fuente: AHC. Fondo gobernación (manuscritos). Sección distritos y municipios. Legajo $\mathrm{N}^{\circ}$ 13. Años 1842-1865.

Por otro lado, el censo trae a colación el número de personas que habitaba el departamento, la cual era de 30.207, aproximadamente. Ese es el total que nos da el censo encontrado, pero si rectificamos esa información nos damos cuenta que la suma total de la población que trae ese censo es de sólo 27.973. Es decir, que harían falta unos 2234 para llegar al total presentado por el 
censador de Mompox, aunque si tenemos en cuenta que el total de la población del Distrito de Sucre y la de su correspondiente Aldea estaban deterioradas y, por otro lado, hicieron falta anotar la del Distrito y la Aldea que no se pudieron registrar por encontrarse en la parte deteriorada del censo, entonces podemos deducir que esos 2234 pobladores que hacen falta se hallaron repartidos en los respectivos Distritos y Aldeas.

Pero, un mes después de levantado ese censo se dividió el Estado en cinco departamentos: Cartagena, Mompox, Corozal, Sabanilla y Sinú. Pero en esta división Magangué ya no aparece como distrito del departamento de Mompox, sino que se encuentra adscrito al de Corozal ${ }^{61}$. Y, posteriormente, en 1859 se crearon tres más: Sabanalarga, Carmen y Magangué. A este último se le entregó la jurisdicción sobre las poblaciones que serían sus correspondientes distritos: Achí, Ayapel, Cascajal, Caimito, Boyacá y Sucre (ver cuadro 5). Es decir, entre 1852 y 1859 se formaron todas las provincias que luego conformarían el Estado Soberano de Bolívar ${ }^{62}$.

Cuadro 5: División de los departamentos de Magangué y Mompox en 1859

\begin{tabular}{|c|c|c|c|}
\hline $\begin{array}{c}\text { Departamento de } \\
\text { Magangué }\end{array}$ & $\begin{array}{c}\text { Número de } \\
\text { habitantes por } \\
\text { distritos }\end{array}$ & $\begin{array}{c}\text { Departamento de } \\
\text { Mompox }\end{array}$ & $\begin{array}{c}\text { Número de } \\
\text { habitantes por } \\
\text { distritos }\end{array}$ \\
\hline Achí & 1.002 & Hatillo & 459 \\
\hline Ayapel & 2.550 & Loba & 2.075 \\
\hline Boyacá & 1.827 & Majagual & 3.398 \\
\hline Caimito & 1.400 & Margarita & 1.827 \\
\hline Magangué & 5.027 & Mompox & 9.350 \\
\hline Sucre & 1.805 & Simití & 2.213 \\
\hline Total & 13.611 & Morales & 2.224 \\
\hline
\end{tabular}

Fuente. AHC. Gaceta de Bolívar. Cartagena. Octubre 9 de 1859.

En 1860 Magangué fue transformado en provincia integrada por los distritos de Achi, Boyacá (con la agregación de Tacaloa), Magangué (con las agregaciones de Guaso, Retiro, San Sebastián y Tacasaluma), Yatí, Majagual, Sucre (con las agregaciones de otero y los pueblos situados en la parte oriental del cauca que pertenecen a Magangué) y Palmarito ${ }^{63}$ (ver cuadro 6). La provincia fue creada para que convergiera la vasta subregión momposina usando para sus comunicaciones la red de caños y ciénagas que caracterizan a esta parte de la depresión ${ }^{64}$. No obstante, habrá que preguntarnos ¿qué sucedió con los anteriores distritos que habían conformado el extinguido departamento de Magangué un año atrás?

\footnotetext{
${ }^{61}$ AHC, "Lei de 13 de noviembre de 1857 sobre división territorial", en Gaceta del Estado Soberano de Bolívar, Cartagena, 22 de noviembre de 1857.

${ }^{62}$ Ver: AHC, "Decreto de 30 de julio, creando los departamentos del Carmen, Magangué y Sabanalarga", en Gaceta del Estado Soberano de Bolívar, Cartagena, 1859; S. P. Solano, R. Flórez y W. Malkún, "Ordenamiento territorial”, pp. 88-89 y 102 .

${ }^{63}$ BBC, Gaceta Oficial del Estado de Bolívar, Cartagena, 29 de enero 1860; AHC, "Cuadro de la división del Estado de Bolívar, arreglado a la ley de 27 de Enero de 1860", Gaceta Oficial del Estado de Bolívar. Cartagena, 1860.

${ }^{64}$ S. P. Solano, R. Flórez y W. Malkún, “Ordenamiento territorial”, pp. 94-95.
} 
Cuadro 6: División de la Provincia de Magangué, 1860

\begin{tabular}{|c|c|c|}
\hline Distritos & Aldeas & Población \\
\hline Achi & Tacaloa y Cascajal & 1002 \\
\hline Boyacá & $\begin{array}{c}\text { Guaso, Retiro, San } \\
\text { Sebastián y Tacasaluma }\end{array}$ & 4480 \\
\hline Magangué & Otero & 547 \\
\hline Yatí & Garzal, Cucharal, & 2400 \\
\hline Majagual & 1805 \\
\hline Sucre & & 1816 \\
\hline Palmarito & Tentura y Hato-Nuevo. & Total 13.237 \\
\hline
\end{tabular}

Fuente: AHC. Gaceta Oficial del Estado Soberano de Bolivar. Cartagena, Marzo de 1860.

Pues bien, siguiendo los preceptos estatuidos por la constitución de 1853 que establecía un orden basado en provincias, distritos, aldeas, etc. y basándose en las leyes dictadas por el Estado soberano de Bolívar, la provincia de Magangué comenzó a organizar su territorio en base a estos órganos administrativos. Una carta enviada por el gobernador de la provincia, Rafael González, al señor Secretario General del Estado Soberano da cuenta de estas reorganizaciones que se venían haciendo al interior de la provincia:

Magangué, mayo 7 de 1860. Sr. Srio[secretario] jral [general] de Estado.

Cascajal distt ${ }^{\circ}$ [distrito] antes que lo formaba con la agregación de Tacaloa solo mide dos miriámetros a la cabezera de este distt $^{\circ}$ [Magangué] i con quien está mas inmediata. De aquel (Cascajal) a Tacaloa mide tres leguas tres cuadras. De este (Tacaloa) al distt ${ }^{\circ}$ de Yatí dos miriámetros cinco kilómetros en igual distancia Cascajal con Yatí. Demanera que Tacaloa por su pocicion con la de su cabezera que lo es el distt ${ }^{\circ}$ de Boyacá están perfectam ${ }^{\text {te }}$ en los estremos opuestos de la provincia es decir; Tacaloa al norte donde principian los limites esta $\mathrm{i}$ Boyacá al sur puede decirce casi al confin de ella De Tacaloa a Boyacá hai una distancia de mas de quince miriámetros que los separan Esto mismo ze [ha] informado a esa Sria antes de ahora haciendo esta misma observación con mas que Boyacá con el Achí por estar en contacto, debían formar ambos un distt ${ }^{\circ}$ porque ninguno de los dos merecen el predicamento por si solo de ser distt tal el estado de arruinamiento en que se encuentran aquellos... ${ }^{65}$

En 1865, se organizó la provincia de Magangué siguiendo, al parecer, gran parte de lo estipulado por Rafael Gonsález en su carta de 1860, porque, como se aprecia en el cuadro 3 Boyacá, Tacaloa y Cascajal formaban un distrito; pero Boyacá se hallaba más cercana a Achí que a Tacaloa y Cascajal, por lo tanto el gobernador Gonsález pide que “...Boyacá con el Achí por estar en contacto, debían formar ambos un distt ${ }^{\circ} . .$. . Mientras que Cascajal debido su

\footnotetext{
${ }^{65}$ Hemos tratado de mantener la ortografía del original. Solo hemos hecho algunas aclaraciones para dar mayor sentido al texto y aparecen entre corchetes. AHC, manuscritos, Fondo gobernación, Sección distritos y municipios, Legajo ${ }^{\circ} 13$, Años $1842-1865$.
} 
cercanía con Magangué ( 2 miriámetros) deberían formar otro y Tacaloa con Yatí que sólo los separaba 2 miriámetros cinco kilómetros, también deberían conformar otro distrito. Pues bien, la Convención Constituyente del Estado Soberano de Bolívar en 1865 así lo decretó el 4 de Mayo, declarando en su artículo $9^{\circ}$ sobre división territorial que,

La Provincia de Magangué se compone de los siguientes distritos: Achí, con la agregación de Boyacá; Yatí, con la agregación de Tacaloa; San Sebastián de Madrid, con las agregaciones de Padilla, Guaso, Retiro y Tacasaluma; Magangué, con la agregación de Cascajal; Majagual; Sucre, con las agregaciones de Otero y los demás pueblos del lado oriental del Cauca; y Palmarito ${ }^{66}$.

Además de la reorganización de la provincia, la carta del gobernador Gonsález nos da a entender que algunos distritos debieron ser relegados de esa categoría, ya que, según el gobernador de la mencionada provincia “...ninguno de los dos [se refiere a Boyacá y a Achí] merecen el predicamento por si solo de ser distt tal el estado de arruinamiento en que se encuentran aquellos...". Y en otra carta enviada anteriormente señalaba que "estos diztritoz que [...] están en este predicamento solo merecen por su estructura la de aldeaz tal el estado de decadencia en que yacen"67.

Por lo visto algunos distritos fueron relegados de esa categoría y se convirtieron en aldeas y, por ende, sus correspondientes aldeas pasarían a agregarse al distrito más cercano, así como lo hace saber Clemente Canabal gobernador de la provincia de Magangué en 1870, quien de manera contradictoria en su informe de ese año dice lo siguiente:

A mi manera de entender deben conservarse los distritos que actualmente figuran componiendo la provincia de mi mando, con el esmerado interés que el gobierno se forma siempre por el agradecimiento i bien estar de todo el estado esceptúo a Palmarito que debe ser suprimido de la categoría de distrito i repartido entre los de Majagual i Sucre. Por la dilijencia de visita que ha practicado i pasado en copia al poder ejecutivo, se habrá informado de que aquella entidad es una burla. ${ }^{68}$

Empero, el año anterior, el gobernador de la provincia de Magangué también se percataba de la problemática de suprimir algunos distritos. Sin embargo, no pretendía que esto se llevara a cabo, dado que alegaba que "en vez de suprimir algunos [distritos], se debe por el contrario, tratar de consolidarlos en cuanto sea posible, a fin de que se pongan a la altura que les

\footnotetext{
${ }^{66}$ Negrillas nuestras para subrayar los distritos que pedía el gobernador González en 1860 que fueran reorganizados. Ver: AHC, Gaceta del Estado de Bolívar, Cartagena, mayo de 1865. Aunque Tacaloa fue segregada de Boyacá y agregada a Yatí en 1860, ver: AHC, Gaceta Oficial del Estado Soberano de Bolivar, Cartagena, diciembre de 1860.

${ }^{67}$ AHC, manuscritos, Fondo gobernación, Sección provincias, Legajo n 38, Años 1857-1880.

${ }^{68} \mathrm{AHC}$, "Informe anual del gobernador de la provincia de Magangué", en Gaceta de Bolívar, Cartagena, 7 de agosto de 1870; AHC, "Informe anual del gobernador de la provincia de Magangué", en Diario de Bolívar, Cartagena, 6 de octubre de 1875 .
} 
corresponde" 69 . No obstante, los siguientes gobernadores de la provincia hicieron caso omiso a dicho llamado, pidiendo la supresión del ya mencionado distrito de Palmarito: en 1870 Clemente Canabal $^{70}$ y en 1871 Marcos Pérez ${ }^{71}$, respectivamente. Quienes al parecer, lograron dicho objetivo, es decir, la eliminación o supresión del distrito de Palmarito, relegándolo a la categoría de aldea. Ya que, en 1873, Manuel Drago en su informe menciona los distritos que conformaron la provincia en dicho año, pero ahí no aparece el nombre de Palmarito ${ }^{72}$. Esta supresión se llevó a cabo en el año de 1872 de acuerdo al artículo $5^{\circ}$ de la ley de 28 de Noviembre de ese año, sobre división territorial, el que señalaba: "eliminase el distrito de Palmarito, en la provincia de Magangué y agregase al de Majagual, en la misma provincia" 73 .

Todo esto nos lleva a pensar en los siguientes cuestionamientos ¿por qué los gobernadores querían o pedían la supresión de algunos Distritos? ¿Cuáles eran las condiciones necesarias para seguir siéndolo, o en su defecto, para elevar una aldea a la categoría de distrito? Varias son las respuestas que podemos rescatar al respecto de estas cuestiones, empecemos por el primer planteamiento. Algunos gobernadores pedían la supresión de ciertos distritos porque, primero, implicaba tener ciudadanos aptos ${ }^{74}$ para ocupar los puestos públicos en dichas entidades; segundo, por factores económicos y un tercer elemento sería la poca población de los distritos o la dispersión de ella.

En ese sentido, el gobernador de la provincia de Magangué en 1860, Rafael González, señala que:

\begin{abstract}
Al proceder el infrascrito ha hacer los nombramientos para el surtimiento de los empleados que se requiere para la constitución de distrito ha encontrado tropiezos casi insuperables [...] tales han sido con los distritos de Achi, Boyacá y Palmarito que por su posición local no se encuentra el personal presiso que debe desempeñar los destinoz puez en elloz no se encuentra acaso la tercera parte de individuos que sepan leer i escribir en quienez solo debe recaer dichoz destinoz. Estos diztritoz que por la ley de su creación están en este predicamento solo
\end{abstract}

\footnotetext{
${ }^{69}$ AHC, "Informe anual del gobernador de la provincia de Magangué", en Gaceta de Bolívar, Cartagena, 12 de septiembre de 1869.

${ }^{70} \mathrm{AHC}$, "Informe anual del gobernador de la provincia de Magangué", en Gaceta de Bolívar, Cartagena, 1870.

${ }^{71} \mathrm{AHC}$, "Informe anual del Gobernador de la provincia de Magangué", en Gaceta de Bolívar, Cartagena, 13 de agosto de 1871.

${ }^{72}$ AHC, "Informe anual del Gobernador de la provincia de Magangué", en Gaceta de Bolivar, Cartagena, 25 de octubre de 1873.

${ }^{73}$ AHC, "Ley de 28 de noviembre de 1872, sobre división territorial", en Gaceta de Bolívar, Cartagena, 8 de diciembre 1872. Otros distritos también pasaron por esta situación, tales fueron los casos de: el Distrito de San Fernando en la provincia de Mompox en 1867, luego fue erigido nuevamente en distrito en 1869, tres años después fue vuelto a ser eliminado de esa categoría, en 1872 y al siguiente fue erigido otra vez; el distrito de Achí en la provincia de Magangué fue suprimido en 1867, entre otros. Ver: AHC, "Ley 15 de octubre de 1867", en Gaceta de Bolívar, Cartagena, 1867; "ley reformatoria de 3 de diciembre de 1868", en Gaceta de Bolívar, Cartagena, 1869; "Ley de 28 de noviembre de 1872", en Gaceta de Bolívar, Cartagena, 1872; "Ley 37 de 15 de diciembre de 1873", en Gaceta de Bolivar, Cartagena, 1873. Cabe mencionar que el problema de supresión y emanación de distritos no sólo se presentó en estas dos provincias, sino en todo el Estado Soberano de Bolívar, véase: AHC, en Gaceta de Bolívar, Cartagena, 1852; AHC, en Gaceta de Bolívar, Cartagena, 1868; AHC, en Gaceta de Bolívar, Cartagena, 1872; AHC, en Gaceta de Bolívar, Cartagena, 1873.

${ }^{74}$ Roicer Flórez, "Ciudadanos y vecinos: un acercamiento al proceso de construcción del ciudadano en Cartagena durante el siglo XIX”, en Historia Caribe, 11, 2006, pp. 113.
} 
merecen por su estructura la de aldeaz tal el estado de decadencia en que yacen. ${ }^{75}$

Esta carta plantea la eliminación de los distritos mencionados porque es poca la población letrada de dichas comunidades, por consiguiente no habrá quien los gobierne localmente. Palmarito es un caso particular porque durante casi todo nuestro período de estudio fue el que más sufrió para mantener la categoría de Distrito, debido, tal vez, a esta situación. Ya que varios gobernadores, como ya hemos visto, alegaban en contra de él la misma razón para suprimirlo, veamos algunos de ellos:

Si he pedido que se elimine el distrito de Palmarito, es porque allí no hai ciudadano alguno aparente o apto para desempeñar los puestos públicos. Mejor regido está por autoridades ajenas que por las de el mismo $^{76}$.

De algo parecido se quejaba el gobernador de dicha provincia el año posterior, pero este por lo menos reconocía el papel del cura como personaje idóneo en dicho distrito; según el gobernador:

El único distrito que merece eliminarse por ahora es el de Palmarito, siendo imposible organizar allí ninguna especie de administración, pues exceptuando al cura, no hai otra persona allí que sepa leer i escribir ${ }^{77}$.

En ambos casos, se plantea la eliminación del distrito de Palmarito, por falta de personas aptas "para desempeñar los puestos públicos"; ya que para que hubiese alguna especie de administración se debía por lo menos, saber "leer i escribir" y según los gobernadores en el caso del distrito de Palmarito sólo el cura estaba capacitado para cumplir su función. Pero el analfabetismo no era un problema particular de las provincias de Magangué y Mompox, puesto que, como lo ha señalado Roicer Flórez, este era un problema del Estado Soberano, en general, de ahí que se viera afectado el funcionamiento normal de su administración ${ }^{78}$.

Por otro lado, y siguiendo con los argumentos señalados por los gobernadores para que se llevara a cabo la supresión de algunos distritos nos encontramos con lo planteado por el gobernador de la provincia de Mompox en 1868, a la asamblea legislativa. Fernando Sánchez, encargado de ese destino, arguye lo siguiente:

Las ocho entidades municipales que actualmente componen la provincia, pudieran mui bien reducirse a cuatro o cinco, de los cuales ninguno tuviera de población menos de cuatro mil habitantes.

\footnotetext{
75 AHC, manuscritos, Fondo gobernación, Sección provincias, Legajo n 38, Años 1857-1880.

${ }^{76} \mathrm{AHC}$, "Informe anual del gobernador de la provincia de Magangué", en Gaceta de Bolívar, Cartajena, 1870.

77 AHC, "Informe anual del Gobernador de la provincia de Magangué", en Gaceta de Bolívar, Cartagena, 13 de agosto de 1871.

${ }^{78}$ R. Flórez, Región y autonomía en el Caribe colombiano.
} 
No menos de veinte i dos mil cuenta toda la provincia, aunque del censo terminado de 1867, aparece tener solo diez i ocho mil novecientos diez. Pero no puede esperarse exactitud de ese dato creado por individuos que sin responsabilidad por una parte, i sin remuneracion por otra, mal pudieran hacer gastos para trasladarse a todos los apartados puntos en que se halla diseminada a largos trechos la poblacion de la provincia. La elevación al rango de distrito de poblaciones que carecen de elementos para sostenerlo, es el descredito de las instituciones federales.

Distritos en que difícilmente se haya quienes sirvan los destinos de alcalde, de concejales, de juez, de secretarios de estos, de procurador, de tesorero, i que carecen de escuelas primarias, cárceles i cementerios, debieran ser relegados al rango inferior de aldeas $^{79}$.

Aquí llaman la atención varias cosas, primero, que el gobernador quería agrupar varios distritos para que cada uno tuviera una mayor población que a través de los impuestos podría contribuir de mejor manera al tesoro del Estado con ello se hacía notar menos el estado de arruinamiento en que se hallaba la provincia, en particular y el Estado en general, es decir, si se muestra una provincia con una distribución distrital más pequeña, pero con una considerable suma económica, va a ser más atractiva que una en donde hay una variedad de distritos pero con un aporte poco significativo. Y si le sumamos que en ellos se "...carecen de elementos necesarios para sostenerlo", tales como, personal idóneo indispensables para que haya un normal funcionamiento de las instituciones del Estado. En pocas palabras lo que nos deja ver el gobernador es que para él y para las provincias es más conveniente y representativo poseer distritos con mayor población que tener más distritos con menor población, y por consiguiente, con gentes menos idóneas para representar la cosa pública. Puesto que,

La diseminación de una pequeña población en un vasto territorio; la naturaleza de este, cubierto de montes, selvas i llanuras pantanosas, a través de las cuales son difíciles las vías de comunicación; el ardor del clima; la feracidad de la tierra, que sin grandes esfuerzos del hombre, prodiga a este profusamente sus dones; i la jenial indolencia heredada de nuestros progenitores, son las causas que frecuentemente se enumeran para esplicar el atraso material de nuestro país ${ }^{80}$.

Otro factor que podía convertirse en problema para los distritos pobres era el económico. De ello nos damos cuenta, además de lo expuesto anteriormente, si miramos con atención lo expresado por el gobernador de Magangué en 1875:

La lei de impuesto sobre la renta ha surtido sus efectos, habiéndose ya consultado i resuelto los puntos de ella que se habian encontrado

\footnotetext{
${ }^{79} \mathrm{AHC}$, "Informe anual del gobernador de la provincia de Mompos", en Gaceta de Bolívar, Cartagena, 27 de agosto de 1868.

${ }^{80} \mathrm{AHC}$, "Informe anual del gobernador de la provincia de Mompos", en Gaceta de Bolívar, Cartagena, 17 de septiembre de 1868 .
} 
dudosos por esta Gobernacion. Pero sí ocurre observar que segun el artículo 42, los distritos en donde no pueda repatirse i cobrarse la suma de ciento veinte pesos anuales señalados como mínimun, seran suprimidos i anexados al mas cercano de la misma provincia. Parece ésta una pena impuesta al distrito; pero como toda pena supone delito o falta, i todo delito, voluntad para verificar el hecho punible, i en la mayor parte de las ocasiones los distritos que no puedan contribuir no lo haran, nó porque no tengan voluntad sino por no estar sus habitantes en posibilidad, i sujetar el derecho que se tenga para ser entidad distritorial, gozando de todos los requisitos necesarios para ello, a una suma de dinero, es un acto a todas luces injusto i que deprime el sentimiento de la dignidad en vez de enaltecerlo: ésto es decir en otros términos, el pobre no tiene derecho porque no tiene dinero. Así pues, por las razones enunciadas debería suprimirse esa disposicion de la referida lei ${ }^{81}$.

Esto nos demuestra la importancia que tuvo el factor económico como requisito para ser y seguir siendo entidad distritorial, pues si no se cumplía con "la suma de ciento viento pesos anuales señalados como minimun" corrían el riesgo de ser "suprimidos i anexados al más cercano de la misma provincia". De esto era que se quejaba el gobernador quien, en vez de pedir la supresión de algunos distritos que no pudieran contribuir con el impuesto sobre la renta, está solicitando la eliminación de "esa disposicion de la referida leí". Puesto que la considera como una pena impuesta a los distritos "que no puedan contribuir [...] nó porque no tengan la voluntad sino por no estar sus habitantes en posibilidad de hacerlo".

De otro lado, nos hace saber que en muchos distritos pobres, contrario a otros, si había personal idóneo para que siguiera funcionando la entidad distritorial y lo único que podía derrumbarlos era dicha ley, ya que para él era injusto e innecesario "...sujetar el derecho que se tenga para ser entidad distritorial, gozando de todos los requisitos necesarios para ello, a una suma de dinero...". En otras palabras el gobernador está reclamando los derechos que se le quitaban a estas entidades, por el hecho de no contar con la suma necesaria para seguir siéndolo: “... el pobre no tiene derecho porque no tiene dinero". Más adelante, señala en esa dirección que: "toda lei que mejore la condición del acomodado tan solo por ser acomodado con perjuicio del pobre, es falta de equidad y establece un jermen de desigualdad." Reafirmando su inconformidad con la forma como se estaba manejando la organización del Estado.

Para responder el segundo planteamiento anteriormente mencionado con respecto a las condiciones necesarias para ser y seguir siendo distrito, debemos tener en cuenta todas las anteriores mencionadas que en suma podemos considerar las siguientes: debía contar con un personal idóneo apto para ejercer los puestos públicos; aumentar la población de los distritos, o más

${ }^{81} \mathrm{AHC}$, "Informe anual del gobernador de la provincia de Magangué", en Diario de Bolívar, Cartagena, 6 de Octubre de 1875. 
bien, reunir la población existentes en pocos distritos; y un tercer factor impuesto por las leyes del Estado Soberano, el cual era contribuir con una cantidad económica suficiente, anualmente.

Pero, además, nos encontramos con una cuarta característica que podía ser considerada importante para que una aldea fuera tenida en cuenta para alcanzar la categoría "distritorial", ella es, la tradición o antigüedad de un pueblo. Así como lo argumenta el gobernador de la provincia de Magangué en 1870, Clemente Canabal, cuando pide que, “...Se eleve a la categoría de distrito el caserío de El Retiro que pertenece hoy al de Madrid. Alego a favor de los antes dicho que El Retiro es una población antigua en donde habitan ciudadanos bastante propios para desempeñar la cosa pública" ${ }^{82}$.

De hecho, si nos vamos al periodo colonial y miramos las poblaciones fundadas o refundadas por Antonio De la Torre y Miranda en 1774, nos damos cuenta que El Retiro era la segunda población con mayor cantidad de personas en esa zona, con un total de 197 vecinos y 1229 personas, sólo la antecedía Magangué con 287 vecinos y 1415 personas (ver cuadro 7). Posteriormente, El Retiro aparece en la lista de los pueblos sobre los cuales ejercería jurisdicción el Cantón de Magangué en $1824^{83}$. Esto nos da a entender que para ese tiempo el Retiro debió ser un pueblo importante para que fuera tenido en cuenta como para ser administrado por un ente gubernativo mayor.

Cuadro 7: Poblaciones fundadas o refundadas por Antonio de la Torre y Miranda en 1774, en esta zona de la depresión momposina

\begin{tabular}{|c|c|c|}
\hline Población & Vecinos & Personas \\
\hline Cascajar & 131 & 555 \\
\hline Tacaloa & 119 & 561 \\
\hline Magangué & 287 & 1415 \\
\hline San Sebastián de Madrid & 99 & 593 \\
\hline El Retiro & 197 & 1229 \\
\hline Tacasaluma & 109 & 596 \\
\hline
\end{tabular}

Fuente: José P. Urueta. Documentos para la historia de Cartagena. Tomo IV, Cartagena. 1890, pp. 33-64.

Por consiguiente, estos debieron ser algunos de los argumentos a los que se refería dicho gobernador. Y atendiendo a esta solicitud y teniendo en cuenta dichos argumentos se creó el distrito de El Retiro en 1873, mediante el artículo $9^{\circ}$ de la ley 37 del 15 de Diciembre de 1873. Este artículo aducía lo siguiente:

Créase el distrito del Retiro en la provincia de Magangué, el cual se compondrá de la agregación de Guaso y los caseríos que existen desde la boca de abajo de Panzeguita hasta la boca de Higuerones por ambas

\footnotetext{
${ }^{82}$ AHC, "Informe anual del gobernador de la provincia de Magangué", en Gaceta de Bolívar, Cartagena, 7 de agosto de 1870.

${ }^{83}$ S. P. Solano, R. Flórez y W. Malkún, “Ordenamiento territorial”, pp. 94-95.
} 
vías y de la agregación del Retiro que será la cabecera. Estos caseríos y agregaciones quedan segregados de los distritos a que pertenecen ${ }^{84}$.

\section{A manera de conclusión}

La vida política, económica y social de la Colombia del siglo XIX estuvo inmersa en una serie de conflictos de esta índole. Ejemplo de ello fueron las diversas guerras civiles que presenció dicha centuria. La derrota de unos y el triunfo de otros se reflejó en la instauración de nuevas y diversas constituciones que difundían los alcances y las visiones de los nuevos mandatos recién instaurados.

El tinte político y económico que suscitaron estos conflictos fue grande. Obtener primacía política y económica y controlar a través de estos móviles a los demás y a las demás regiones, ciudades, provincias o pueblos fueron la iniciativa de quienes controlaron los diversos poderes, en contraposición de quienes los querían acaparar. Por lo tanto fueron los alicientes que provocaron las devastadoras guerras civiles de la primera mitad del decimonónico siglo colombiano. Esto era propiciado por el afán de unos por doblegar a los otros e imponer jerarquías territoriales que les eran dadas por los privilegios heredados de décadas o centurias pasadas; pero en la segunda mitad de ese siglo estos privilegios desaparecieron y muchas de esas ciudades debieron articularse a una economía de exportación y las que no pudieron hacerlo debieron competir con "ciudades nuevas" que se estaban articulando mejor a ese orden.

Mompox, además de tener conflictos con la ciudad heroica, tuvo que afrontar, para la segunda mitad del siglo XIX, el auge que tomó su ciudad vecina. La villa momposina entra en un marcado estancamiento económico en este periodo. Por lo que tuvo que ceder espacios de poder a Magangué, luego de haber sido creada la provincia de ese nombre. En consecuencia se reconfiguraron los viejos conflictos que existían entre estas ciudades, ya que a Mompox se le suprimió gran parte de su territorio que fue anexionado a la recién creada provincia y los límites entre estas siempre fueron confusos durante el periodo estudiado. Entonces, su elite, inicia todo un proceso de políticas destinadas a recuperar, no solo el territorio perdido, sino también el poder político y económico que durante mucho tiempo había ejercido en la zona.

En ese orden de ideas, los conflictos que presentaron estas dos provincias fueron característicamente territoriales, políticos y económicos. Los cuales tuvieron como trasfondo la lucha por el poder o por los poderes (político, económico y social) en la depresión momposina. En muchos casos estos conflictos eran empezados por alguno de los actores sociales más pudientes de la provincia quienes se valían de su influencia política y económica para

${ }^{84}$ AHC, “Ley 37 de 15 de Diciembre de 1873”, en Gaceta de Bolívar, Cartagena, 1873. 
buscar encarar los conflictos. Lo que conllevo, de una u otra forma, a los diversos auges y estancamientos de una y otra provincia. Y en su defecto a disputas entre ellas.

Los distritos de cada provincia, a su vez, estaban envueltos en sus propias luchas por mantener sus categorías y las aldeas por ostentar una mejor posición en el entramado organizacional de la provincia. Por lo que se sometieron a una serie de pruebas y demostraciones para permanecer ostentándola en el caso de los distritos; o para escalar en el orden territorial, para el caso de las aldeas y cantones. Para ello, tuvieron que cumplir con una serie de requisitos emanados por los gobernadores de las provincias o por el presidente del estado soberano. De esta forma, las principales personalidades de cada provincia, distrito, aldea y cantón, buscaron alianzas con los notables del estado, o de la provincia para mantener a sus localidades en el orden actual o en uno mejor.

Es decir, hacían uso del poder del que estaban investidos para atacar a la otra provincia, o distrito, o en su defecto para defenderse o defenderla. A través de sus nexos clientelares, familiares, matrimoniales, económicos, de partido, de amistad, etc., que les permitía instaurar alguna reclamación o defenderse de alguna acusación, esto es, se escudaban detrás de sus redes para hacer cualquier reclamo, protesta, petición, o para defender sus intereses personales, clientelares y los de la provincia. Lo anterior se evidencia a través de cartas, informes, memoriales, etc., que dejaron nuestros sujetos históricos.

La diplomacia jugó un papel importante a la hora de la resolución de un conflicto. Ya que la mayoría de estos se confeccionaban en las oficinas, casas y haciendas de las personalidades provinciales y ahí se resolvían. Pero hubo momentos en donde la diplomacia pasó al campo de batalla o al terreno en disputa, en donde muchos se enfrentaron por defender los intereses de aquellos que acaparaban el poder y que en últimas eran los verdaderos beneficiados en estos conflictos. Hemos de suponer que se valían del analfabetismo y pobreza que caracterizaba a la mayoría de las personas de estas provincias para manipularlos. Y a las relaciones que establecían con pequeños y medianos productores de las comarcas más apartadas de la provincia para ejercer influencia político-social en ellos.

Muchas de estas personalidades fueron comerciantes, ganaderos agricultores, hacendados, o combinaban varias de estas actividades, pero rara vez se le vio actuando en la vida política local o regional. Tal vez, porque no les quedaba tiempo, no querían hacerlo o porque eran analfabetas. Sin embargo, estaban conectados con las redes políticas y económicas de la provincia y ayudaban o se veían afectados por las cuestiones políticas de la misma. Entre ellos encontramos a Cayo G. Ribón, Oscar A. Trespalacios, Tomas Alvarado, Santiago Álvarez, Buenaventura Caro ${ }^{85}$, Manuel Martínez González, Manuel

${ }^{85}$ BBC, Gaceta de Bolívar, Cartagena, 1 de octubre de 1868. 
Villalobos, Benito Pontón, Pedro Cerpa, Manuel García Ardébol, Jorge Delgado, Ezequiel Cordero, entre otros ${ }^{86}$.

Las mujeres jugaron un papel activo que merece una investigación más exhaustiva. Muchas de estas fueron grandes ganaderas, comerciantes, agricultoras y hacendadas y algunas debieron actuar en la política local, aunque no tenemos indicios directos pero si insinuaciones de que lo hubieran hecho, además, porque eran madres de muchos de esos "nuevos políticos" que florecieron en estas provincias y esposas y/o viudas de otros.

Algunas de las más destacadas matronas de estas provincias fueron: Lucia Viñas de García, María Josefa Bustos, Benedicta Riano, Martina Cantero, Manuela Barrera, entre otras ${ }^{87}$. Manuela Barrera es quien ilustra mejor este caso. Era una mujer con gran poder económico e influencia en la provincia de Mompox y en el Estado: madre del clan Obeso. En Enero de 1868 le conceden una licencia para destilar y rectificar aguardientes, pero meses después de habérsele concedido dicha licencia, la alberca destinada a tales oficios se le rompió, ante esta situación ella pide al Poder Ejecutivo que se le exima de pagar el impuesto sobre aguardiente, ya que no está “...obligada a pagar el derecho de patente hasta que la fábrica en referencia se encuentre en ejercicio, que será sin falta alguna el 1. de Octubre próximo”. Más adelante argumenta,

Mi petición es justa, Ciudadano Presidente, por que si es verdad que el derecho expresado se causa destilando i rectificando el aguardiente con las condiciones que establece la lei, dicho derecho no puede tener lugar aun subsistiendo la licencia correspondiente, cuando por una fatalidad inesperada o no prevista, llega a imposibilitarse la destilación ${ }^{88}$.

El mes de julio se resolvió la situación en el juzgado de la provincia, en donde fueron a declarar, a petición de la señora Barrera, algunos vecinos momposinos entre ellos Pantaleón German Ribón. Así, la Asamblea terminó aprobando dicho reclamo a favor de la agraviada.

\section{Bibliografía}

\section{Fuentes primarias}

Archivo Histórico de Cartagena (AHC).

Biblioteca Bartolomé Calvo (BBC).

Biblioteca Luis Ángel Arango (BLAA).

\footnotetext{
${ }^{86}$ BBC, Gaceta de Bolívar, Cartagena, 23 de agosto de 1868.

${ }^{87}$ BBC, Gaceta de Bolivar, Cartagena, $1^{\circ}$ y 11 de octubre de 1868.

${ }^{88}$ BBC, Gaceta de Bolivar, Cartagena, 11 de octubre y 6 de diciembre de 1868 .
} 


\section{Fuentes primarias impresas:}

Balmaseda, Francisco, "La feria de Magangué”, en Boletín Historial, n. ${ }^{\circ 45-46,}$ Cartagena, Academia de Historia de Cartagena, 1919.

Madiedo, Manuel María, Nuestro siglo XIX, Bogotá, Imprenta de Nicolás Pontón, 1868.

Nieto, Juan José, Geografía histórica, estadística y local de la provincia de Cartagena, república de la Nueva Granada descrita por cantones, Cartagena, 1839.

Parra, Aquileo, Memorias (1825-1875), Bogotá, Editorial Incunable, 1982.

Pérez, Felipe. Episodios de un viaje (1864/5), Bogotá, Editorial ABC/Ministerio de Educación de Colombia, 1946.

Salzedo Del Vilar, Pedro, Apuntaciones historiales de Mompox, Tip. Democracia, 1938.

\section{Fuentes secundarias:}

Aguirre Rojas, Carlos, "La corriente de los Annales y su contribución al desarrollo de la historia económica en Francia", en: Cuadernos de Trabajo, 3, Xalapa, Universidad Veracruzana, 1998.

Blanco, Wilson, Historia del Carmen de Bolivar y su tabaco en los Montes de María. Siglos XVIII-XX, Cartagena, Universidad de Cartagena, 2009.

Bloch, Marc, Introducción a la Historia, México-Madrid-Buenos Aires, fondo de cultura económica, 1952.

Bloch, Marc, La sociedad feudal: la formación de los vínculos de dependencia, México, UTEHA, 1958.

Bloch, Marc, La sociedad feudal: las clases y el gobierno de los hombres, México, UTEHA, 1958.

Bloch, Marc, Historia rural francesa, Barcelona, Crítica-Grijalbo, 1978.

Bloch, Marc, "El método comparativo en historia", en Perspectivas de la historiografía contemporánea, México, SEP, 1976.

Borja, Miguel, Estado, sociedad y ordenamiento territorial en Colombia, Bogotá, CEREC Universidad Nacional, 2000.

Braudel, Fernand, "Los juegos del intercambio", en Civilización material, economía y capitalismo, siglos XV-XVIII, Tomo II, Madrid, Alianza Editorial, 1984.

Burke, Peter, Venecia y Ámsterdam. Estudio sobre las elites del siglo XVII, Barcelona, Gedisa Ed., 1996. 
Bushnell, David, Una nación a pesar de sí misma, Bogotá, Planeta, 2007.

Calvo de Hoyos, Luz Dary, Juan José Nieto. Regionalismo y Poder político en el Estado de Bolivar, 1858-1866, Tesis para optar título de historiadora Universidad de Cartagena, 2002.

Colmenares, Germán, "La economía y la sociedad coloniales. 1550-1800”, en Nueva Historia de Colombia, Tomo I, Bogotá, Planeta, 1989.

Conde, Jorge, Espacio, Sociedad y Conflictos en la provincia de Cartagena 17401815. Barranquilla, eds. Universidad del Atlántico.

Conde, Jorge, "Reformas Borbónicas y reordenamiento del espacio en el Nuevo Reino de Granada. El caso de la provincia de Cartagena", en Historia Caribe, 1, Barranquilla, Universidad del Atlántico, 1995, pp. 5-24.

Cruz, Edwin, "El federalismo en la historiografía política colombiana (1853-1886)", en Historia Crítica, 44, Bogotá, Universidad de los andes, 2011, p. 104-124.

Del Valle Porto, Alfonso, Compendio monográfico de la villa de Magangué, Medellín, 1992.

Fals Borda, Orlando, El Presidente Nieto, Bogotá, COED, Universidad Nacional/Banco de la República/ El Áncora Editores, 2002.

Fals Borda, Orlando, Mompox y Loba, Bogotá, Carlos Valencia Editores, 1980.

Febvre, Lucien, La tierra y la evolución humana, Cervantes, Barcelona, 1925.

Febvre, Lucien y Demangeon, Albert, Le Rhin. Problèmes d'histoire et d'Economie, Librairie Armand Colin, París, 1935.

Gutiérrez, Juan F., “Transportes y ocupación del territorio en Colombia”, en Diana Ceballos (Ed.) Prácticas, territorios y representaciones en Colombia, 1849-1960, Medellín, Universidad Nacional, 2009.

Flórez Bolívar, Roicer, El uso privado de la autoridad pública en el Estado Soberano de Bolivar, 1863-1878, Cartagena, Tesis para optar el título de Magister en Historia, Universidad Pedagógica de Tunja-Universidad de Cartagena, 2007.

Flórez Bolívar, Roicer, "Resguardos indígenas, ciudadanía y ganadería en el Estado Soberano de Bolívar, 1863-1875", en Trenzado 1, Cartagena, Grupo de Trabajo Memoria, 2008.

Flórez Bolívar, Roicer, "Indígenas y ciudadanía en el Estado Soberano de Bolívar, 1863-1875”, en Historia y Sociedad, 16, Medellín, Universidad Nacional, 2009, pp. 49-72.

Flórez Bolívar, Roicer, "El sistema de arrendamiento y la monopolización de los ingresos fiscales en el Estado Soberano de Bolívar, 1860-1878", en El Taller de la Historia, 1, Cartagena, Universidad de Cartagena, 2009, pp. 13-40. 
Flórez Bolívar, Roicer, "Caña de azúcar y aguardiente en el Estado Soberano de Bolívar, 1857-1886”, en Cuadernos de Desarrollo Rural, 6, Bogotá, 2009, pp. 3557.

Flórez Bolívar, Roicer, Región y autonomía en el Caribe colombiano. El caso del Estado Soberano de Bolivar, 1857-1886, Proyecto ganador de la XII convocatoria de las becas de investigación cultural Héctor Rojas Herazo del observatorio del Caribe.

Wong Hiu, Alberto, "Las finanzas públicas en el Estado Soberano de Bolívar, 18571886", en Historia y Pensamiento, 3, Barranquilla, Universidad del Atlántico, 1999, pp. 28-36.

Jiménez, Orian y Pérez, Edgardo, La Mojana: medio ambiente y vida material en perspectiva histórica, Medellín, Universidad de Antioquia, 2007.

Laurent, Muriel, El contrabando en Colombia en el siglo XIX. Prácticas y discursos de resistencia y reproducción, Bogotá, Universidad de los Andes, 2008.

Lemaitre, Eduardo, Historia General de Cartagena, Tomo IV. La República, Bogotá, Banco de la República, 1983.

Malkún, William, Educación y política en el Estado Soberano de Bolívar 18571886, Cartagena, Tesis de maestría en historia, Universidad de CartagenaUniversidad Pedagógica y Tecnológica de Colombia, 2008.

Meisel, Adolfo, "Esclavitud, mestizaje y hacienda en la provincia de Cartagena 1533-1851", en Gustavo Bell (ed.), El Caribe Colombiano, Barranquilla, Uninorte, 1988.

Meneses Urzola, José, Presencia e influencia italiana en Colombia: El caso de Magangué, 1890-1930. Redes sociales y circuitos comerciales, Medellín, trabajo presentado para optar al título de Historiador, Universidad de Antioquia, 2009.

Miranda Gil, Eloy, Disputas territoriales, políticas y económicas entre las provincias de Magangué y Mompox, 1853-1875, Cartagena, trabajo de grado para optar al título de historiador, Universidad de Cartagena, 2013.

Nichols, Theodore, Tres puertos de Colombia estudio sobre el desarrollo de Cartagena, Santa Marta y Barranquilla, Bogotá, 1973.

Ocampo, Javier, Historia básica de Colombia, Bogotá, Plaza \& Janes Editores, 2007.

Ocampo, Javier, "La patria Boba", en Cuadernillos de Historia, Bogotá, Panamericana, 1998.

Ocampo, Javier, "El proceso político, militar y social de la independencia”, en Nueva Historia de Colombia, Tomo II. Bogotá, Planeta, 1989, 
Peñas Galindo, David y Arquez, Oscar, Espacio, poblamiento y sociedad en la región de la de-presión momposina, Medellín, Ed. Lealón, 1994.

Posada Carbó, Eduardo, El Caribe colombiano. Una historia regional, 1870-1950, Bogotá, COED, Banco de la República/ El Áncora Editores, 1998.

Restrepo, Carlos, Constituciones de la primera república liberal, 1853-1856, Bogotá, Universidad Externado de Colombia, 1979.

Restrepo, Jorge y Rodríguez, Manuel, "La actividad comercial y el grupo de comerciantes de Cartagena a finales del siglo XIX", en Estudios sociales, 1, Medellín, FAES, 1986.

Roa Valdelamar, Cristian, Ferias comerciales de Magangué (1858-1902), Cartagena, tesis para optar título de historiador, Universidad de Cartagena, 2002.

Salazar, Stella y Aldana, Eduardo, "Magangué en la encrucijada", en Fabio Zambrano Pantoja, (comp.), Poblamiento y ciudades del Caribe colombiano, Bogotá, Observatorio del Caribe Colombiano/Fonade/Universidad del Atlántico, 2000.

Solano, Sergio Paolo, Puertos, sociedad y conflicto en el Caribe colombiano, 18501930, Bogotá, Ministerio de Cultura-Observatorio del Caribe colombianoUniversidad de Cartagena, 2003.

Solano, Sergio Paolo y Flórez, Roicer, "Resguardos indígenas ganadería y conflictos sociales en el Bolívar Grande, 1850-1875", en Historia Crítica, 34, Bogotá, Universidad de los Andes, 2007, pp. 92-117.

Solano, Sergio Paolo y Flórez, Roicer, "Indígenas, mestizaje, tierra y poder en el Caribe colombiano, siglo XIX", en Indiana. 26, Berlín Ibero-Amerikanisches Institut, 2009.

Solano, Sergio Paolo y Flórez, Roicer, "La expropiación de las tierras del resguardo de Tubará y las normas jurídicas de la época", en Justicia, 12, Barranquilla, Universidad Simón Bolívar, 2007, pp. 81-89.

Solano, Sergio Paolo, Flórez, Roicer y Malkún, William, “Ordenamiento territorial y conflictos jurisdiccionales en el Bolívar Grande 1800-1886", en Historia Caribe, 13, Barranquilla, Universidad del Atlántico, 2008, pp.65-119.

Solano, Sergio Paolo, Flórez, Roicer y Malkún, William, "Ganaderos y comerciantes: el manejo del poder político en el Estado Soberano de Bolívar (Colombia), 1857-1886", en Historia y Sociedad, 18, Medellín, Universidad Nacional de Colombia, 2010, pp.15-42.

Striffler, Luis, El rio San Jorge, Cartagena, 1958.

Tirado, Álvaro, Descentralización y centralismo en Colombia, Bogotá, Fundación Friedrich Nawman-Oveja Negra, 1983. 
Tovar, Hermes, "La historiografía sobre Cartagena de indias en el siglo XVIII", en Haroldo Calvo y Adolfo Meisel (eds.), Cartagena de indias y su historia, Cartagena, Universidad Jorge Tadeo Lozano, Seccional Caribe y Banco de la República, 1997.

Uribe Uribe, Carlos, Poblamiento y relaciones subregionales en el bajo Magdalena: Brazo de Loba, 1770-1900, Medellín, Tesis de Historia Universidad Nacional, 2002.

Uribe, Diego, Las constituciones de Colombia, Madrid, Cultura hispánica, 1997.

Verbel, Grey, "Elites y redes de poder en torno al proyecto regenerador. Cartagena, 1874-1892", en El Taller de la Historia, 1, Cartagena, Universidad de Cartagena, 2009.

Zambrano, Fabio, Ciudad y territorio. El proceso de poblamiento en Colombia, Bogotá, Academia Colombiana de Historia/Instituto francés de Estudios Andinos, 1993. 